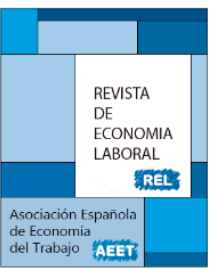

\title{
LA DEVALUACIÓN SALARIAL EN ESPAÑA TRAS LA REFORMA DEL 2012: ARTICULACIÓN JURÍDICA Y EFECTOS ECONÓMICOS
}

\author{
Diego Dueñas Fernández ${ }^{1 *}$, Luis Gómez Rufián ${ }^{\&}$ \\ *Universidad de Alcalá e Instituto de Análisis Económico y Social, \\ \&Universidad Carlos III de Madrid
}

Recibido Julio 2015; Aceptado Octubre 2015

\section{Resumen}

Este artículo presenta un análisis sobre la reforma laboral llevada a cabo en España en el año 2012 y sus consecuencias económicas. En concreto, muestra cuál ha sido la magnitud de la devaluación salarial en términos nominales y reales, y cómo ésta, contrariamente a lo que se esperaba, no ha servido para resolver los problemas de desempleo del mercado de trabajo español, pese a colocar el poder adquisitivo de los trabajadores en un nivel similar al de principios de la década de los '90. Finalmente se ilustran algunos de los posibles errores que se han podido cometer a la hora de abordar la dirección y la intensidad de la reforma laboral.

Palabras clave: mercado de trabajo, salario, tasa de paro, reforma laboral, competitividad.

Clasificación JEL: K31, J08, J30, J83.

\section{Abstract}

This paper presents an analysis of the labour reform which has been implemented in Spain during 2012 and its economics consequences. Specifically, it shows what has been the magnitude of internal devaluation developed in Spain by important nominal and real wage cuts and how it, inversely of what was expected, has not been helpful to resolve the problems of Spanish unemployment despite having pushed back the real wages (the purchasing power of workers) to levels of the early nineties. Finally, it exposes some of the possible errors that probably the government has done in planning and intensity of the reform.

Key words: Labour market, Wage, Unemployment rate, Labour market reform, Competitiveness.

JEL Classification: K31, J08, J30, J83.

\footnotetext{
${ }^{1}$ Autor para correspondencia: diego.duenas@uah.es
}

(C) Revista de Economía Laboral 


\section{Introducción}

El mercado de trabajo español se encuentra en un importante cruce de caminos. Por una parte, la crisis económica actual se ha materializado de forma tajante en una parálisis del mercado laboral. Si bien en la economía española se ha dejado de destruir empleo, aun no existe una creación de puestos de trabajo a un ritmo considerable a la par que necesario. Por otra, las instituciones gubernamentales correspondientes han efectuado ya una serie de reformas que deberían haber servido de catalizador del aumento del empleo, el consumo y la producción española. Habiendo pasado ya más 3 años de la puesta en marcha de la reforma laboral del 2012, puede que sea el momento de hacer una primera evaluación de cuáles han sido las consecuencias de este conjunto de instrumentos legales que se han implementado en la estructura laboral.

La encrucijada además viene profundamente condicionada por la confrontación que surge desde el punto de vista de la Teoría Económica a la hora de encontrarle una explicación y, consecuentemente, una solución a la coyuntura económica y laboral en la que se encuentra el mercado de trabajo español. En este sentido, diversos organismos nacionales e internacionales se han postulado en contra de las rigideces normativas que regulan nuestro mercado de trabajo, planteando así que una devaluación salarial podría ser el bálsamo que curara los males de los que adolece nuestro entramado laboral.

En cierto modo, el dilema es simple. Por un lado, la corriente ortodoxa apuesta por una devaluación salarial que reduzca los costes empresariales, aumentando así sus beneficios y fomentando la contratación; por otro, la línea post-keynesiana plantea que una reducción de los salarios disminuye el consumo, las ventas y los beneficios de las empresas, aumentando entonces la destrucción de empleo.

En este entorno temporal y con este marco analítico, el objetivo principal de este trabajo es mostrar cuáles han sido los cambios normativos y cuáles han sido las consecuencias de la reforma laboral del año 2012, materializada principalmente en una devaluación salarial, siguiendo los postulados neoclásicos. Tras esta devaluación, los sucesivos capítulos ponen de manifiesto los errores cometidos para que los cambios aplicados no hayan dado los frutos esperados.

Con esta finalidad, la estructura del artículo es la siguiente: en el apartado 2 se muestra la situación previa al año 2012 de la economía española y los fundamentos teóricos del "modelo NAIRU". El tercer 
apartado presenta un resumen jurídico del conjunto de medidas que se han realizado para cambiar la reciente evolución negativa del mercado de trabajo español. En los apartados cuarto y quinto se cuantifica la magnitud de la devaluación salarial en términos nominales y reales, respectivamente. En el sexto apartado se exponen algunas causas por las que la reforma laboral no ha conseguido alcanzar los objetivos previstos. El séptimo apartado propone una teoría alternativa a la Teoría Neoclásica que incorpora al análisis una serie de variables ajenas al conjunto de normas que han reformado el mercado de trabajo español. Por último, en el octavo apartado el artículo presenta las conclusiones derivadas del estudio.

\section{El salario y la NAIRU en España: la situación previa al año 2012}

La reforma del mercado de trabajo llevada a cabo en España en el año 2012 parte de una aproximación a la causalidad de la actual crisis laboral que supone un ambicioso desplazamiento a un plano secundario de factores típicamente keynesianos, relativos a la determinación del empleo en virtud de la demanda agregada durante el ciclo económico, en favor de una interpretación predominantemente neoclásica del desempleo, en la cual las rigideces adaptativas del mercado laboral español constituyen, así, su causa principal ${ }^{2}$.

La justificación in extenso de esta perspectiva se recoge, por un lado, en las diferentes versiones del Plan Nacional de Reformas y del Programa de Estabilidad, y, por otro, en los diferentes informes internacionales emitidos ya sea por el Fondo Monetario Internacional, la Comisión Europea o la Organización para la Cooperación y el Desarrollo Económicos (OCDE) ${ }^{3}$.

El sustento teórico de esta postura analítica, que constituye el enfoque ortodoxo en economía laboral, es el de la conocida "tasa de desempleo no aceleradora de la inflación" (NAIRU, non-accelerating inflation rate of unemployment) (Layard, Nickell y Jackmann, 1991) en torno a la cual oscilaría el desempleo efectivo, determinando que una

\footnotetext{
2 Exposición de Motivos, punto VI, párrafos segundo y tercero, del Real Decreto Ley 3/2012 de 10 de febrero, de medidas urgentes para la reforma del mercado laboral. Boletín Oficial del Estado, de 11 de febrero de 2012.

3 Gobierno de España (2012a). En el mismo sentido, véase la Recomendación de la Comisión Europea de 12 de julio de 2011 relativa al Plan Nacional de Reformas de 2011 de España, por la que se emite un dictamen de la Comisión Europea sobre el Programa de Estabilidad actualizado del Reino de España 2011 - 2014 (Comisión Europea, 2011).
} 
parte mayoritaria del desempleo estaría causada por las rigideces introducidas por la legislación laboral (entendida ésta como un factor exógeno) sobre el funcionamiento eficiente del mercado, existiendo entonces un volumen de desempleo de magnitud directamente proporcional a la intervención legislativa en el mercado laboral, que se mantendría estructuralmente inalterado si no se procede a realizar las reformas pertinentes.

Esta tesis posee un amplio respaldo en la literatura referida a la economía laboral española (Bentolila y Jimeno, 2003; Dolado, Jansen y Jimeno, 2007; Doménech, 2012). Dada esta situación basada en la rigidez de los salarios y la consecuente incapacidad de las empresas de ajustar costes mediante mecanismos alternativos, España, en relación a otros países de su entorno geográfico, conjugaría el mercado laboral más rígido con la tasa de desempleo estructural más elevada.

Así se muestra en el gráfico 1. España ha alcanzado en el año 2012 una tasa de paro próxima al 25 por ciento de su población activa, muy por encima de los valores existentes en Alemania (5 por ciento), Francia (10 por ciento), Italia (11 por ciento), Portugal (16 por ciento) y Reino Unido (8 por ciento). En cuanto a la NAIRU, España es el único país que sobrepasa el valor del 15 por ciento, quedando como el más próximo el valor de Portugal, que es levemente superior al 10 por ciento. Igualmente, es concluyente que la desviación media de la tasa de paro española con respecto a su NAIRU entre 1980 y 2012 es de 3,11 puntos porcentuales mientras que el mismo valor para el resto de países, en media, no llega al 1 por ciento.

Así se recoge en un documento publicado por el Fondo Monetario Internacional en el año 2010 (Fondo Monetario Internacional, 2010): "Los análisis cuantitativos demuestran que el desempleo aumenta en presencia de un sistema de negociación colectiva de centralización intermedia, altas prestaciones por desempleo, una elevada cuña fiscal y una estricta regulación del mercado de productos [...]. El modelo sugiere que la tasa de desempleo de equilibrio [NAIRU] española no ha cambiado mucho desde su máximo nivel durante los últimos 25 años. [...] Con la cuña fiscal, los subsidios de desempleo y la regulación del mercado de productos en líneas generales en la media de la UE-15, la mayor parte de la diferencia en las tasas de desempleo de equilibrio [NAIRU] entre España y la UE-15 parece reflejar el mayor grado de coordinación de la negociación salarial en otros países de la UE-15 [...]. Las reformas para reducir la tasa de desempleo [NAIRU] deben centrarse en avanzar hacia una mayor flexibilidad de la negociación salarial y una combinación de la reducción de las prestaciones por desempleo y la presión fiscal". 
Gráfico 1: Evolución de la NAIRU y de la tasa de desempleo en España y otros países de la Unión Europea, 1980-2012

\section{España}

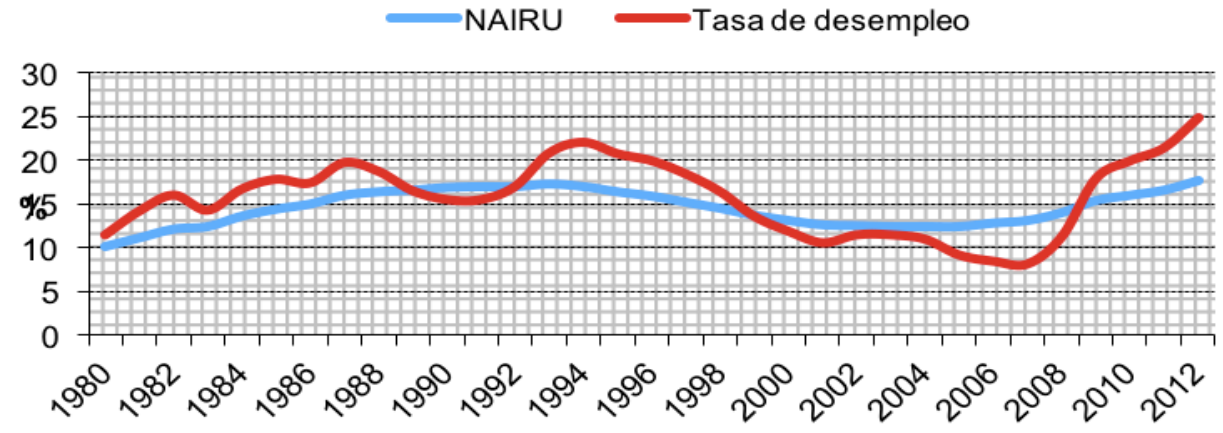

\section{Alemania}

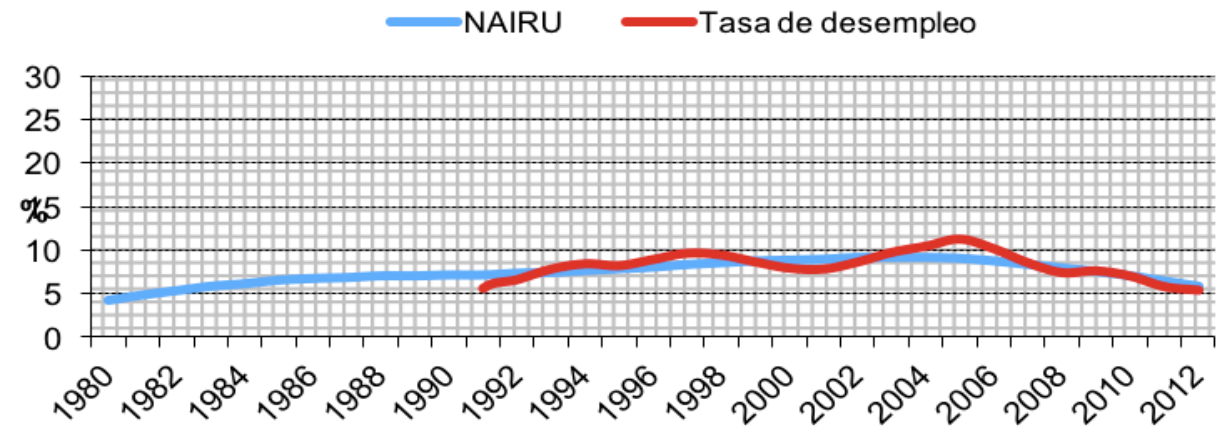

Francia

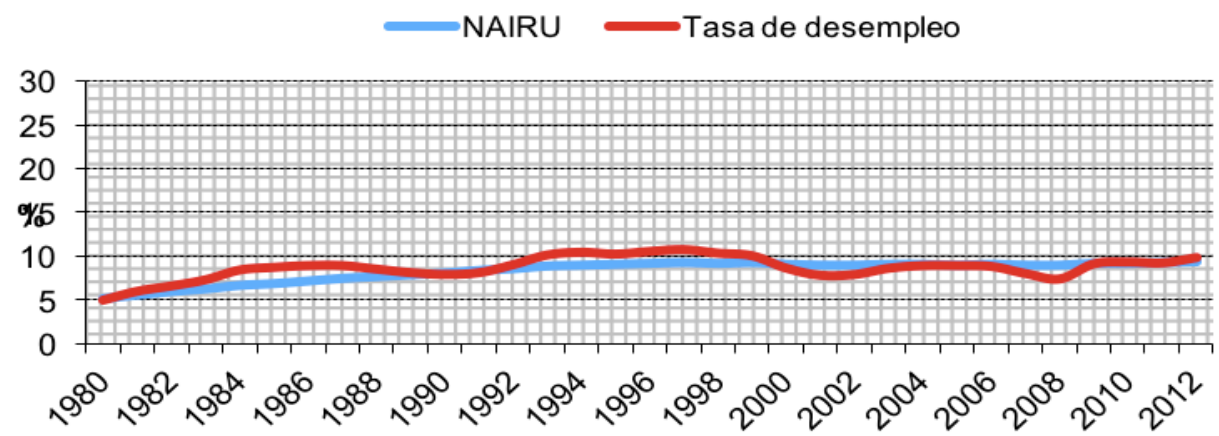

Fuente: AMECO, Comisión Europea. 


\section{Gráfico 1 (continuación)}

\section{Italia}

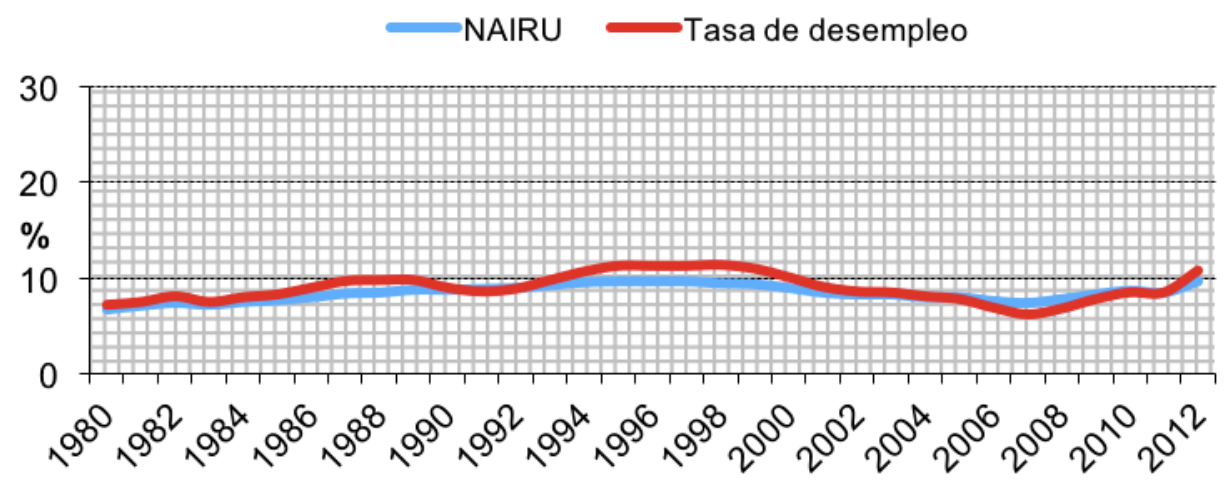

\section{Portugal}

NAIRU Tasa de desempleo

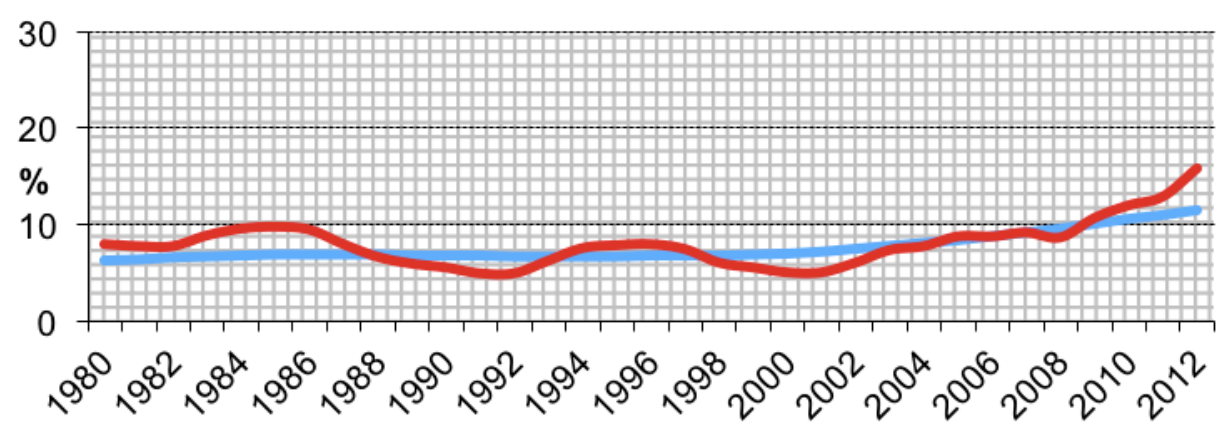

\section{Reino Unido}

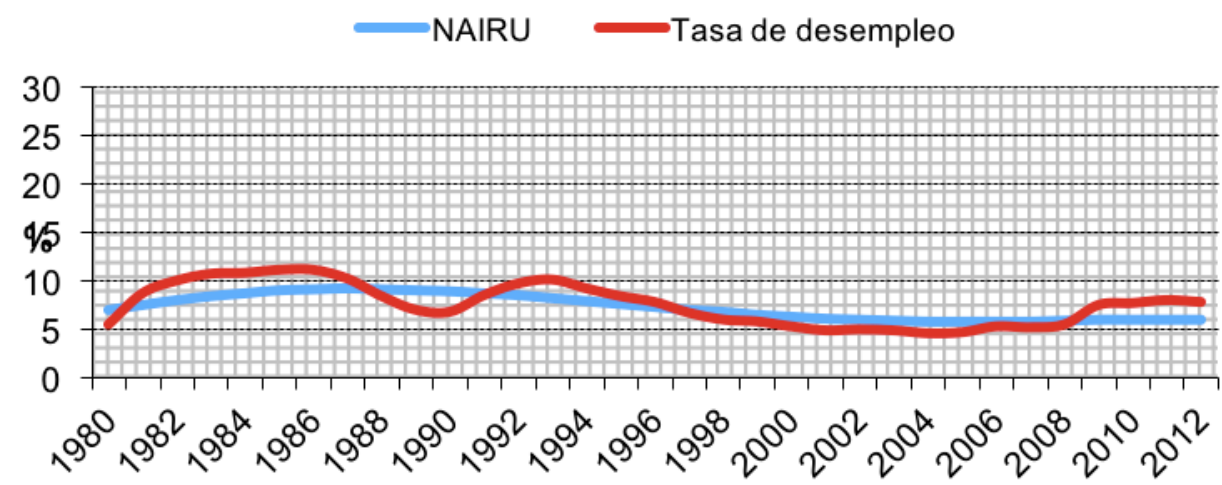

Fuente: AMECO, Comisión Europea. 
La denominación del modelo comentado anteriormente como NAIRU contiene una serie de propiedades que lo convierten en un factor equilibrador entre las pretensiones de los trabajadores y de los empresarios. Ante un crecimiento de la demanda capaz de reducir el desempleo, se genera, a su vez, un incremento de los precios derivado del mayor poder de negociación de los trabajadores, ya que se reduce la bolsa de desempleados que ofrecen trabajo a un salario menor, y los empresarios se ven obligados a ofrecer salarios mayores para atraer a nuevos trabajadores.

Según sus fundamentos, podría alcanzarse temporalmente una tasa de desempleo efectivo inferior a la NAIRU en supuestos de crecimiento económico excepcional, si bien a cambio de un crecimiento no sostenible de la inflación que, además, erosiona la competitividad vía precios de la economía. Esta podría haber sido la experiencia española entre 1998 y 2008, ya que, durante la etapa de crecimiento, sufrió una cierta "espiral precios - salarios" derivada de la negociación de subidas salariales muy superiores a la productividad, siendo entonces repercutidas a los precios.

En el gráfico 2 se observa una tasa de variación de los salarios pactados que ha ido moderadamente en aumento entre el año 2000 y el 2008 , llegando a alcanzar el 4,5 por ciento en este último año, mientras que en la Eurozona se mantuvo relativamente estable con oscilaciones próximas al 1 por ciento. Por su parte, el gráfico 3 presenta un crecimiento de los precios superior en España (siempre por encima del 2 por ciento) que en la Eurozona (donde nunca superó el 1,5 por ciento). Finalmente, el gráfico 4 muestra la diferente evolución de la productividad y de los salarios nominales en nuestro país, manteniéndose en todo momento los segundos por encima de la primera.

Una cuestión significativa que aparece en los tres gráficos anteriores es la divergencia que se produce entre los años 2007 y 2008, ya sea cuando se comparan los datos españoles y los europeos o cuando se evalúa la evolución de los salarios y la productividad en España. En el primer caso, y teniendo en cuenta que se considera el año 2007 como el momento en el que dio comienzo de forma oficial la actual crisis, parece que es diferente la capacidad de reacción en nuestro país y en Europa, siendo ésta más rápida que aquella. En el segundo, la evolución de los salarios nominales se mantiene inerte al cambio de ciclo, tal vez por estar predeterminados (y ser inamovibles en el corto plazo) de forma previa al final del proceso expansivo de la economía española y europea. 
Gráfico 2: Tasa de variación de los salarios nominales pactados en España y en la Eurozona, 2000 - 2008.

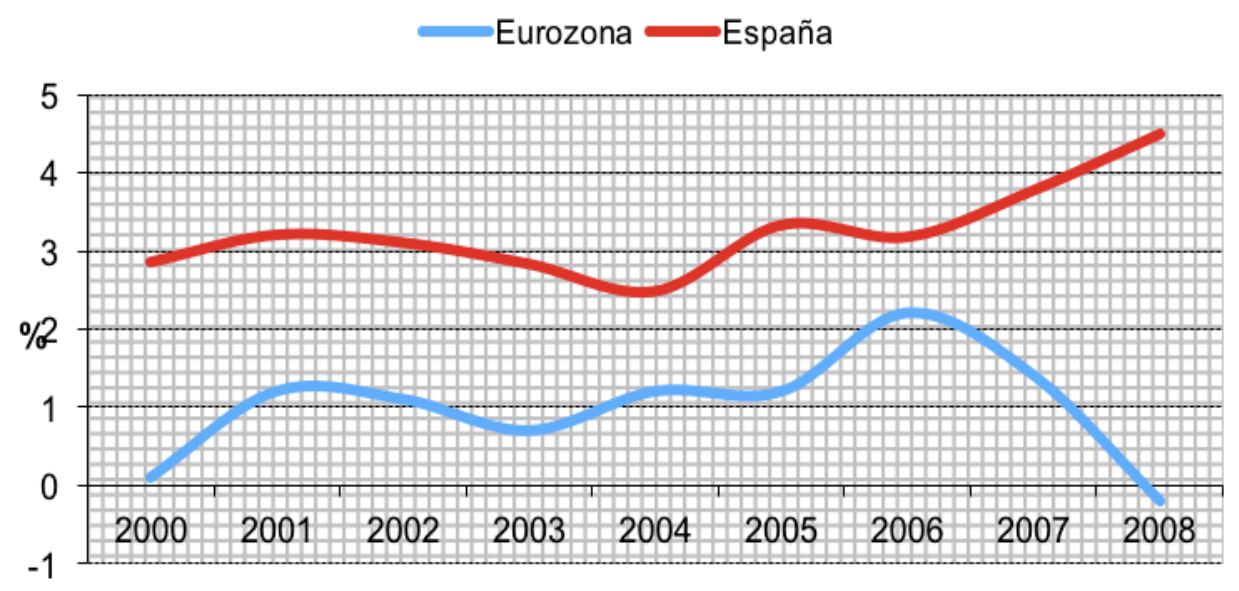

Fuente: Eurostat.

Gráfico 3: Tasa de variación de los precios en España y en la Eurozona, 2001 - 2008

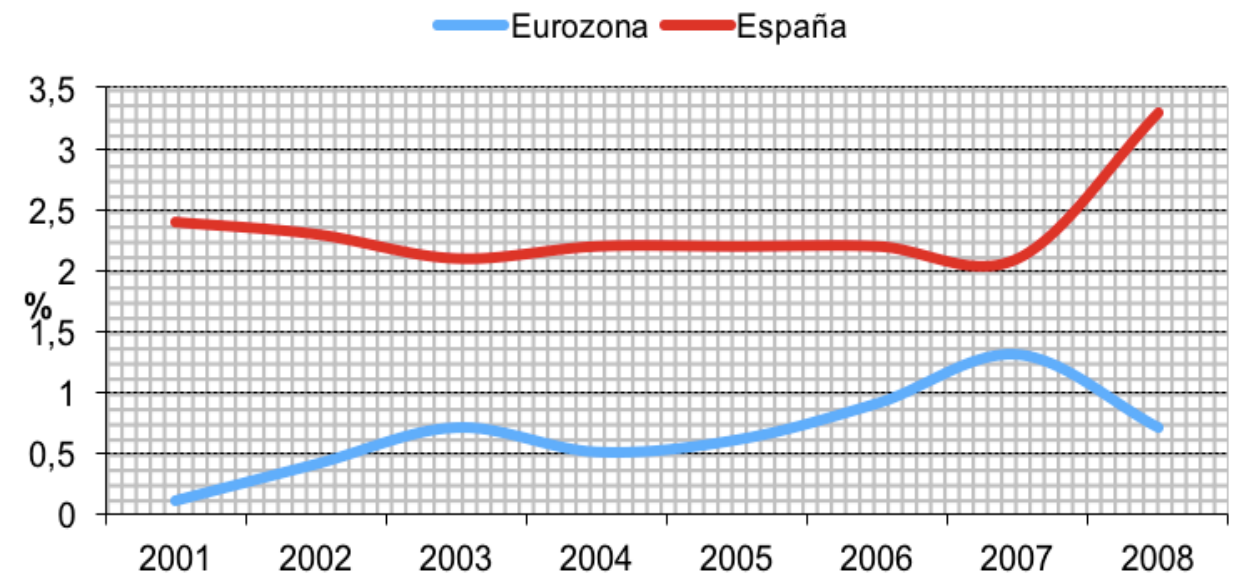

Fuente: AMECO, Comisión Europea; Boletín de Estadísticas Laborales, Ministerio de Empleo y Seguridad Social. 


\section{Gráfico 4: Tasa de variación de la productividad y de los salarios nominales en España, 2000 - 2008}

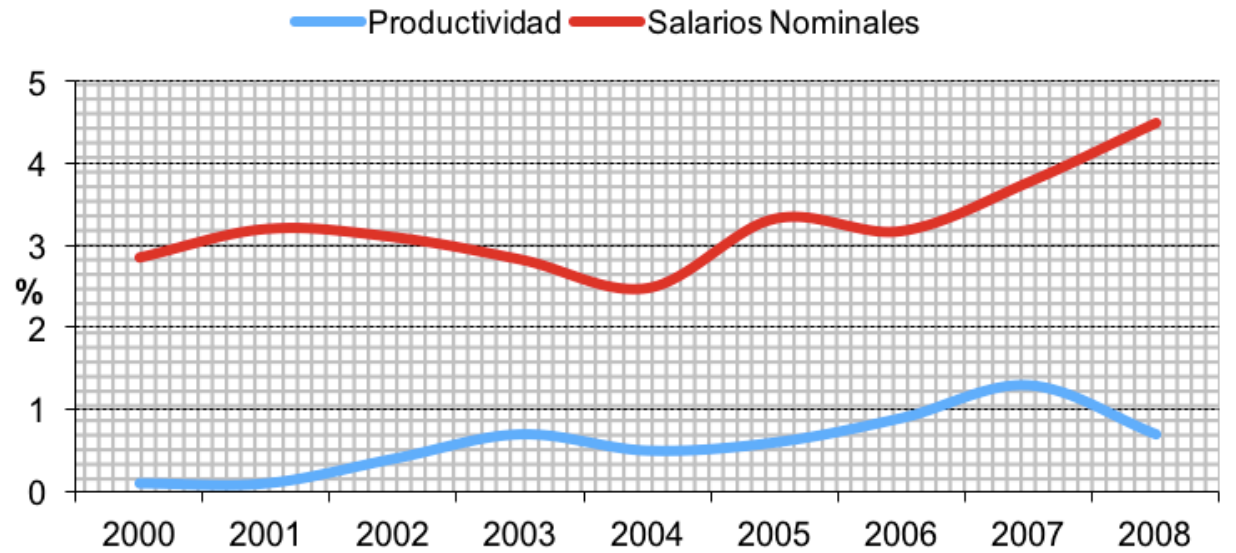

Fuente: AMECO, Comisión Europea; Boletín de Estadísticas Laborales, Ministerio de Empleo y Seguridad Social.

Un resumen institucional de estos datos anteriormente presentados se puede encontrar en el Considerando 15 del Dictamen del Consejo Europeo sobre el Programa de Estabilidad Actualizado del Reino de España (2011 - 2014) (Comisión Europea, 2011) donde se señalaba que "España experimentó una fuerte subida de sus costes laborales unitarios desde finales de los años noventa, lo que implicó un deterioro de su competitividad de precios y de costes. Unas subidas salariales superiores y unos incrementos de productividad inferiores a los de la zona del euro han contribuido a una inflación constantemente superior en España".

En línea con estas palabras, y así se indica en el gráfico 5, entre el año 2000 y el 2008, España acumuló un incremento en los costes laborales nominales próximo al 35 por ciento, muy por encima del que registraron otros países de nuestro entorno como Italia (27 por ciento), Reino Unido (23 por ciento), Portugal (20 por ciento), Francia (17 por ciento) o Alemania (1 por ciento). La tendencia en nuestro país, continuamente creciente, se ve incluso acrecentada entre 2006 y 2008, tres años en los que pasa del 20 al 35 por ciento. 


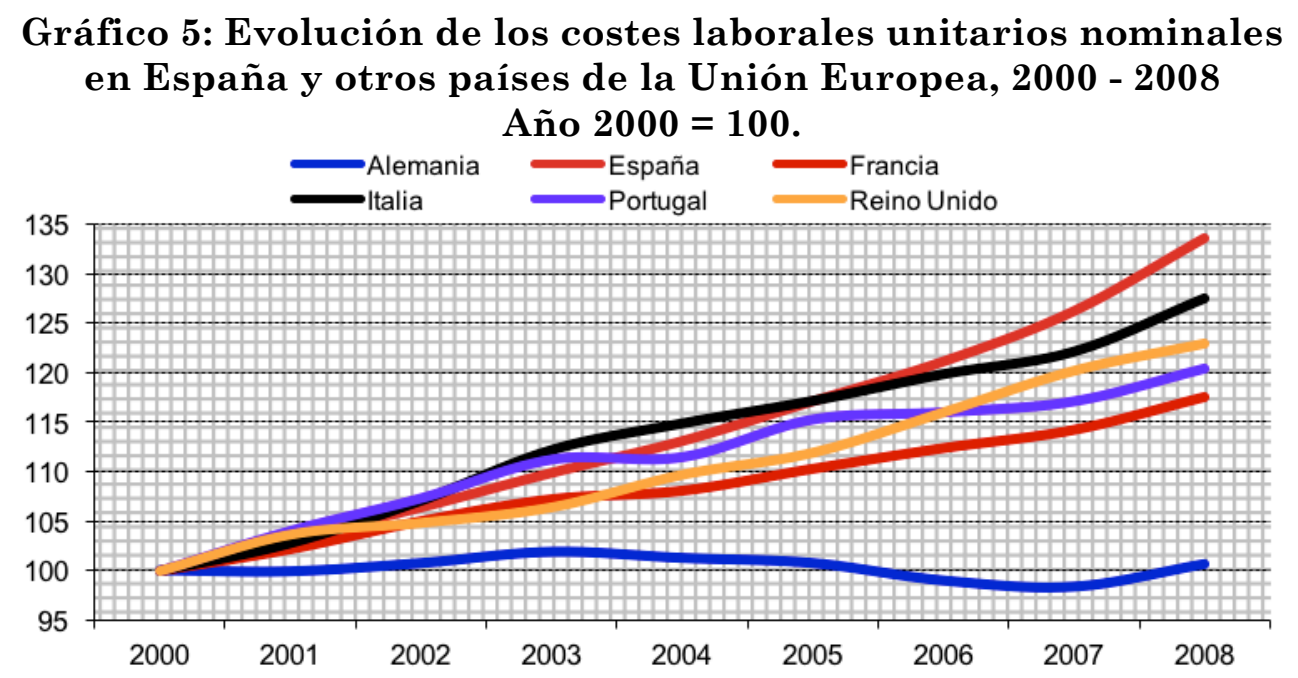

Fuente: AMECO, Comisión Europea.

En el plano de los efectos, esta dinámica, desincentivaría las exportaciones e incentivaría las importaciones, generando un fuerte desequilibrio en forma de un agudo déficit comercial que alcanzó niveles del 10 por ciento del Producto Interior Bruto español en 2007. Y es que, como responsable del mismo, se señala el hecho de que la regulación salarial conjugue el ámbito provincial como unidad de referencia negociadora (sin lógica económica) con el arraigo de la indexación vinculada al Índice de Precios al Consumo (Comisión Europea, 2011). Junto a ello, se añadirían también como factores determinantes la extensa duración pactada de los convenios y, especialmente, la teórica inexistencia de mecanismos de flexibilidad salarial.

Esto es lo que se recoge en el gráfico 6 donde se observa que son mayoría los años entre 2008 y 2012 en los que existen variaciones positivas de los salarios y variaciones negativas de la producción, principalmente en el sector de la construcción, y en menor medida en la industria y en la agricultura. En el sector servicios, pese a que ambas variables registran tasas de variación positivas, siempre es superior la que se refiere a los salarios que la que implica a la producción. Todo ello impediría que las empresas, ante una caída en su margen de beneficios, pudieran proceder a una reducción de costes que mantenga la viabilidad de las mismas, obligando a que el ajuste se traduzca en destrucción de puestos de trabajo. 
Gráfico 6: Asimetría entre la evolución del ciclo económico (tasa de variación interanual de la producción) y el incremento salarial pactado en cada sector económico, 2008 - 2012

Agricultura

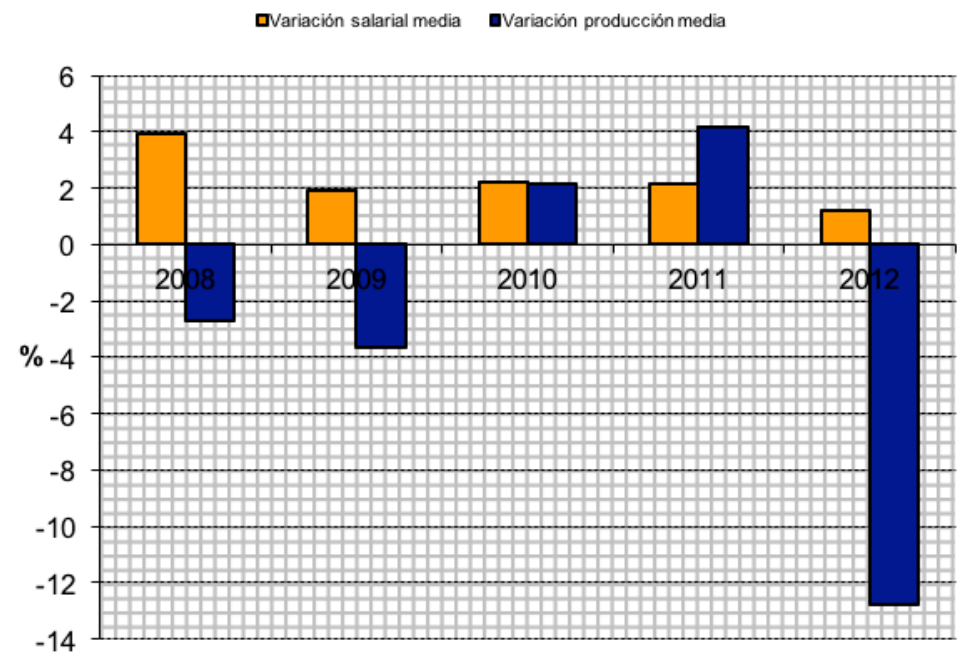

Industria

पVariación salarial media $\quad \square$ Variación producción media

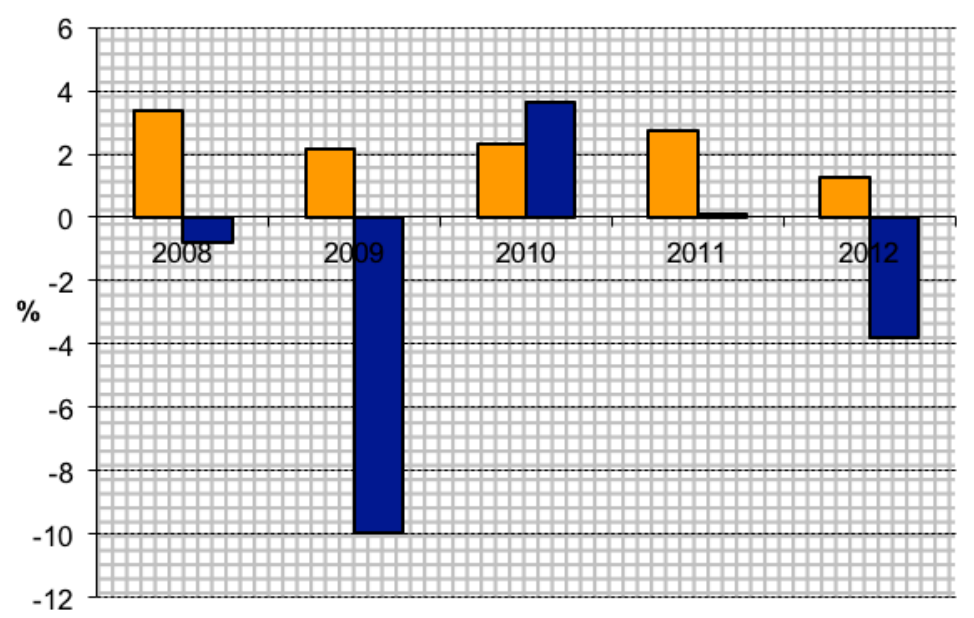




\section{Gráfico 6 (continuación)}

\section{Construcción}

口Variación salarial media $\quad$ VVariación producción media

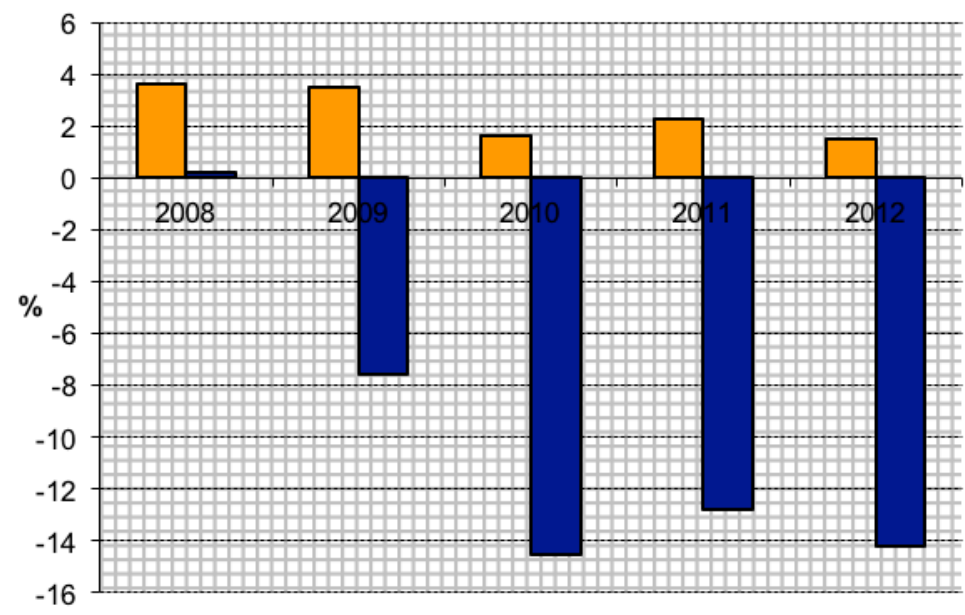

Servicios

口Variación salarial media $\quad$ Variación producción media

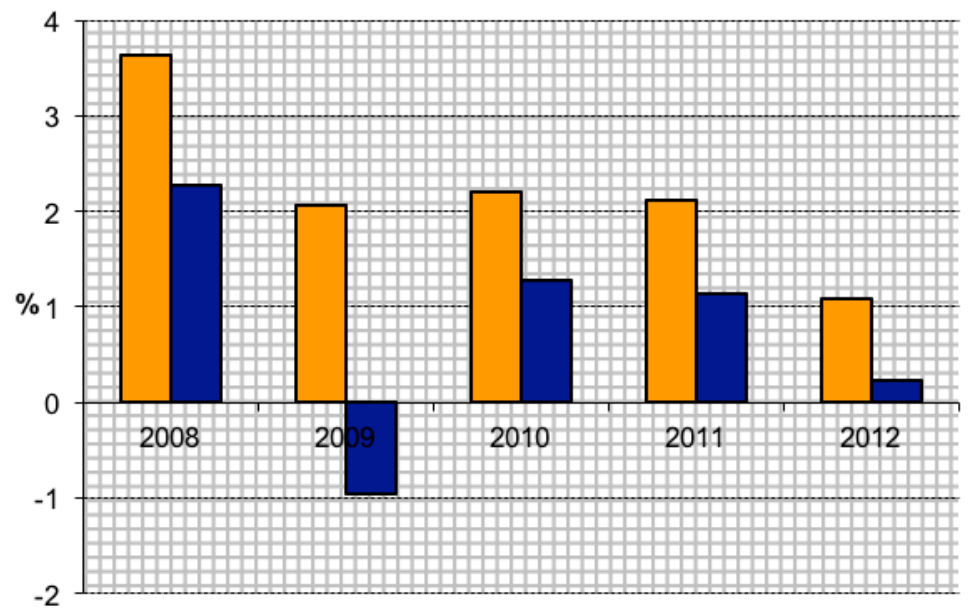

Fuente: Boletín de Estadísticas Laborales, Ministerio de Empleo y Seguridad Social; Contabilidad Nacional de España, Instituto Nacional de Estadística. 
Como conclusión al conjunto de datos anteriores hay que resaltar que algunas voces se han posicionado a favor del desarrollo de una importante reducción salarial a efectos de recuperar la competitividad supuestamente perdida (Dolado, 2012; Bentolila y Jansen, 2012). No obstante, apenas se ha profundizado en el cómo y en el porqué una reducción salarial permitiría la recuperación del empleo y la competitividad, algo que exige una explicación que vaya más allá de la mera estática comparativa. Dicha defensa se articula a través de dos argumentos consecutivos: los denominados "efecto saldos reales" y "efecto Pigou" (Patinkin, 1948).

En cuanto al primero de ellos, relativo a la inversión, entiende que, al disminuir los salarios se producirá una consecuente caída de precios, pues en situación de competencia perfecta, dadas las condiciones de equilibrio de cada empresa, una caída de salarios reduce los costes marginales y, con ello, el punto de equilibrio con los ingresos marginales que determina el precio que han de aceptar las empresas (en cualquier caso, una reducción del consumo - de la demanda conllevaría unos menores precios). Dicha caída de precios supone, en realidad, un crecimiento en términos reales de la oferta monetaria existente, lo que incentiva la petición de préstamos para financiar nuevas inversiones al reducirse el tipo de interés.

En segundo lugar, el denominado "efecto Pigou", relativo también a la inversión pero, sobre todo, al consumo, considera que, al provocarse la mencionada reducción de precios, aumentaría el valor real del ahorro preexistente de los agentes económicos, incentivando el consumo de bienes y servicios y, por tanto, permitiendo a los empresarios encontrar una salida para la nueva inversión, incentivada por la caída de tipos de interés a la que nos referíamos anteriormente. Así, se restablecería el equilibrio, alcanzando de nuevo la producción de pleno empleo, con precios y salarios monetarios inferiores y salarios reales restablecidos tras la reducción inicial.

En resumen, parece que algunas variables que pertenecen o giran en torno al mercado laboral (salarios, productividad, costes laborales unitarios, tasa de paro, NAIRU y producción) se encontraban en una situación que, en su conjunto, sería propiciatoria de la pésima evolución que posteriormente ha desarrollado el mercado de trabajo español. De esta forma, en el año 2012 se llevo a cabo una reforma laboral que tenía como principal objetivo implementar medidas que supusieran una flexibilización de los salarios, entendiendo que esta variable sería el primer engranaje que pusiera en marcha la recuperación económica. 


\section{Articulación jurídica de la flexibilidad salarial}

Una vez planteados algunos de los rasgos principales de la economía española en los años previos a la reforma del 2012, este capítulo pretende exponer cuáles han sido el conjunto de instrumentos jurídicos de flexibilidad salarial reformados en dicho año.

Como es conocido, el salario nominal que percibe un trabajador puede reducirse por dos vías. La primera de ellas de forma directa, basada en la reducción del salario nominal por hora trabajada, la cual vendría determinada a través de 3 cauces:

\section{A) La Modificación Sustancial de las Condiciones de Trabajo $(\mathrm{MSCT})^{4}$}

El primer y más directo mecanismo de flexibilidad interna mediante el cual puede ejecutarse una reducción de componentes salariales viene dado por la Modificación Sustancial de las Condiciones de Trabajo (artículo 41 del Estatuto de los Trabajadores). Mediante este mecanismo el empresario puede disponer de diversos elementos del contrato de trabajo o de las condiciones reguladas en acuerdos o pactos colectivos, decisiones unilaterales de la empresa de efectos colectivos y de condiciones pactadas o dadas a título individual, con el límite en todos los casos de lo dispuesto en el convenio estatutario aplicable, si lo hay.

Este instrumento ha sido objeto de una serie de intensos cambios tendentes a favorecer el poder de disposición empresarial, tales como:

1. Como cuestión central, se reconfiguran las causas que habilitan la utilización de la misma, elemento que se complementa con la desaparición de la denominada "conexión de funcionalidad" o racionalidad justificativa de la misma. Hasta ahora, para la utilización de esta figura se exigía que existieran "probadas razones económicas, técnicas, organizativas o de producción", entendiéndose "que concurren las causas [...] cuando la adopción de las medidas propuestas contribuya a prevenir una evolución negativa de la empresa o a mejorar la situación y perspectivas de la misma a través de una más adecuada organización de sus recursos, que favorezca su posición competitiva en el mercado o una mejor respuesta a las exigencias de la demanda". Ahora, simplemente, se señala que se

\footnotetext{
${ }^{4}$ No existen datos empíricos de esta opción jurídica, a través de los cuales se pudiera
} observar su magnitud y profundidad. 
entenderán como esas probadas razones económicas, técnicas, organizativas o de producción "las que estén relacionadas con la competitividad, productividad $u$ organización técnica o del trabajo en la empresa". En este caso, la magnitud de la ampliación del potencial uso de la medida es obvia, pues en realidad, por la generalidad de la causa, ésta constituye una suerte de causa perpetuamente activada que, además, no está sometida a ningún canon de racionalidad.

2. Se procede a determinar la diferenciación entre modificaciones individuales y colectivas, ateniéndose la norma ahora a un criterio puramente cuantitativo e independiente de la fuente jurídica de la que proviene la modificación. Así, las modificaciones de convenios colectivos extraestatutarios pueden realizarse por esta vía, mientras que las referidas a los estatutarios es enviada al artículo 82.3 del Estatuto de los Trabajadores. Esta nueva clasificación afecta a la impugnación judicial de la medida en detrimento de la capacidad de resistencia del trabajador, pues el cauce procesal aplicable cuando la decisión no alcance los citados umbrales, será en todo caso el fijado en el artículo 138 de la Ley Reguladora de la Jurisdicción Social, sin posibilidad de acumulación de acciones, ni recurso de suplicación, ni la materia es planteable mediante la modalidad procesal de tutela de derechos fundamentales, quedando restringido el procedimiento de conflicto colectivo, en el que sí que intervienen los representantes colectivos, a la impugnación de aquella modificación que supere los umbrales cuantitativos de trabajadores afectados.

3. Adicionalmente, del artículo 50.1a del Estatuto de los Trabajadores se elimina la posibilidad de solicitar la extinción del contrato por modificaciones sustanciales de condiciones de trabajo que redunden en perjuicio de la dignidad o formación profesional de los trabajadores.

4. La decisión de modificar sustancialmente las condiciones de trabajo individual deberá ser notificada por el empresario al trabajador afectado y a sus representantes legales con una antelación mínima de 15 días a la fecha de su efectividad (anteriormente eran 30 días). En el caso de modificación colectiva, se abrirá un periodo de negociación, no superior a 15 días, si bien tal acuerdo no es imprescindible ni constituye un requisito para la efectividad de la modificación. Así, la decisión final en caso colectivo será notificada por el empresario a los trabajadores una vez finalizado dicho periodo de negociación, 
surtiendo efectos en el plazo de los siete días siguientes a su notificación.

5. Se incluye la "cuantía salarial" (y no sólo el "sistema de remuneración") entre las condiciones alterables. No obstante, se trata de un cambio de tipo aclaratorio ya que el listado del artículo 41.1 del Estatuto de los Trabajadores ha constituido tradicionalmente un numerus apertus.

\section{B) La inaplicación o "descuelgue" de convenios (artículo $82.3 \mathrm{del}$ Estatuto de los Trabajadores)}

Como segunda cuestión, se ha realizado una ambiciosa reforma de la inaplicación de convenios colectivos estatutarios, es decir, de aquellos con eficacia general erga omnes. Ello, junto al intento de descentralización de la estructura negociadora, pretende, en teoría, superar la incapacidad de los convenios de ajustarse a la evolución del ciclo económico. Dicha reforma se caracteriza por:

1. Se procede a un cambio en la naturaleza de la figura, que pasa de considerarse un simple "descuelgue salarial" para constituirse en un "descuelgue convencional", es decir, mientras antes de la reforma este mecanismo era válido solo para dejar de aplicar los conceptos salariales, ahora abarca todas las materias recogidas en el listado de la MSCT (si bien en este caso se trata de un numerus clausus). No obstante, se adicionan las mejoras voluntarias a la lista de materias inaplicables.

2. Al igual que ocurre en la MSCT, se produce una relajación en las causas paralelas a la desaparición de la conexión de funcionalidad. No obstante, las primeras pasan a definirse con mayor concreción, si bien dicha concreción, a su vez, está configurada en tales términos que supone una notable ampliación del radio de acción de las mismas. Así, la norma señalaba anteriormente que podrá negociarse la inaplicación cuando la empresa "tenga una disminución persistente de su nivel de ingresos o su situación y perspectivas económicas pudieran verse afectadas negativamente como consecuencia de tal aplicación, afectando a las posibilidades de mantenimiento del empleo en la misma", de modo que, además de la causa, el uso de la figura debía estar obligatoriamente orientado a un objetivo: el mantenimiento del empleo. Sin embargo, la norma ha eliminado dicho objetivo para señalar ahora que: 
a. Por un lado, concurren causas económicas cuando de los resultados de la empresa se desprenda una situación económica negativa, en casos tales como la existencia de pérdidas actuales o previstas, o la disminución persistente de su nivel de ingresos ordinarios o ventas. En todo caso, se entenderá que la disminución es persistente si durante dos trimestres consecutivos el nivel de ingresos ordinarios o ventas de cada trimestre es inferior al registrado en el mismo trimestre del año anterior.

b. Por el otro, concurren causas técnicas cuando se produzcan cambios, entre otros, en el ámbito de los medios o instrumentos de producción; causas organizativas cuando se produzcan cambios, entre otros, en el ámbito de los sistemas y métodos de trabajo del personal o en el modo de organizar la producción; y causas productivas cuando se produzcan cambios, entre otros, en la demanda de los productos o servicios que la empresa pretende colocar en el mercado.

Así, como se ha dicho, aunque se detallan las causas, un examen de las mismas lleva a la conclusión de que su nueva amplitud supone, en realidad, que se ha operado una importante flexibilización, entre otras cosas, por la adición de las causas organizativas, productivas y técnicas.

3. Mientras en la anterior legislación el convenio que podía inaplicarse debía ser obligatoriamente de ámbito superior a la empresa, en la actualidad podrá ser de sector o de empresa, es decir, se permite que las empresas que poseen convenio propio procedan al denominado "autodescuelgue".

4. En cuanto al periodo de negociación, en caso de ausencia de representantes señalados en el artículo 87 del Estatuto de los Trabajadores, y por remisión al artículo 41 de dicho estatuto, se constituirá una "comisión ad hoc" formada por trabajadores de la empresa y ajena a los sujetos colectivos, lo cual es de gran trascendencia ya que el panorama de microempresas que caracteriza la economía española invita a presumir poca capacidad de negociación de dichas comisiones.

5. En términos procedimentales, adicionalmente, y a efectos de evitar las situaciones de bloqueo, se establece un nuevo proceso de negociación con fuerte peso de terceros agentes. En caso de 
desacuerdo, se podrá someter la discrepancia consecutivamente a la Comisión Paritaria, a los mecanismos contemplados en los acuerdos interprofesionales de ámbito estatal o autonómico y finalmente, a la Comisión Consultiva Nacional de Convenios Colectivos cuya resolución (o laudo arbitral) no es de obligado cumplimiento, pudiendo ser recurrido judicialmente.

6. En términos del acuerdo, de un lado, se elimina la obligación de pactar una programación de progresiva recuperación de las condiciones inaplicadas; del otro, en cuanto a la duración del descuelgue, la regulación anterior establecía que la misma quedaba limitada al período de vigencia del convenio con el límite de tres años de duración, referencia que ha sido ampliada hasta el momento en que resulte aplicable un nuevo convenio en dicha empresa.

Así, la utilización de esta figura entre marzo de 2012 y marzo de 2015 se resume en los siguientes aspectos: i) Se han ejecutado un total de 6.012 inaplicaciones que han afectado a un total de 277.330 trabajadores; ii) el 80,1 por ciento de las inaplicaciones han sido realizadas por empresas de menos de 50 trabajadores; iii) el 92,6 por ciento de las inaplicaciones han sido alcanzadas por acuerdo, el 3,8 por ciento por acuerdo de la Comisión Paritaria del convenio, el 0,3 por ciento por laudo en órgano bipartito y el 0,8 por ciento por decisión en el seno de un órgano tripartito; y iv) medido por el número de trabajadores afectados, en el 87,3 por ciento de los casos el elemento a inaplicar fue la cuantía salarial, en exclusiva o junto a otros elementos. Adicionalmente, en el gráfico 7 se muestra el solapamiento temporal que ha existido entre la implantación de esta medida y su ejecución, concentrándose el mayor número de inaplicaciones de convenios a lo largo del año 2013 y principios de 2014.

\section{C) La firma de convenios que rebajan directamente las retribuciones pactadas}

Como vía de reducción salarial, algunos convenios han procedido a renegociarse reduciendo el montante a recibir por los trabajadores en términos salariales tal y como ha venido ocurriendo en las siguientes divisiones de actividad que se muestran en el cuadro 1. Pese a no ser un mecanismo con una amplia utilización, algunos sectores han conocido una reducción salarial considerable. 


\section{Gráfico 7: Total de inaplicaciones de convenios efectuadas por mes, marzo 2012 - abril \\ 2015}

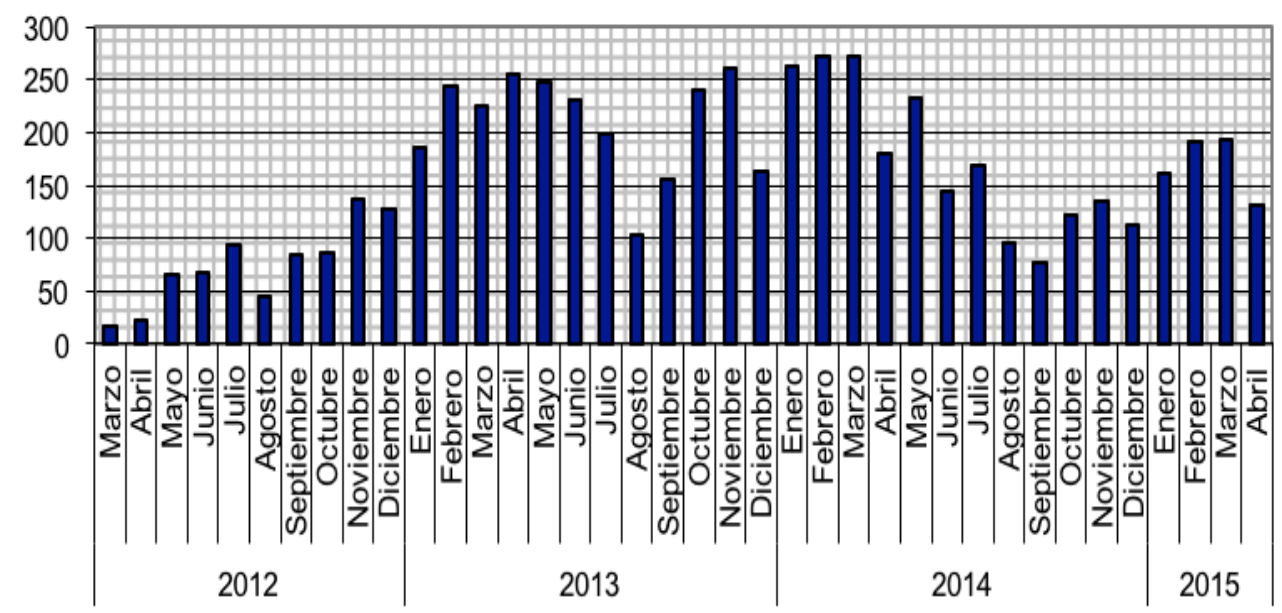

Fuente: Estadística de Convenios Colectivos de Trabajo, Ministerio de Empleo y Seguridad Social.

\section{Cuadro 1: Divisiones de actividad en la que se han pactado} incrementos salariales negativos, $2013-2015$

Divisiones de actividad

05. Extracción de antracita, hulla y lignito

26. Fabricación de productos informáticos, electrónicos y ópticos

51. Transporte aéreo

58. Edición

66. Actividades auxiliares a los servicios financieros y a los seguros

72. Investigación y desarrollo

77. Actividades de alquiler

78. Actividades relacionadas con el empleo

80. Actividades de seguridad e investigación

84. Administración Pública y defensa;

Seguridad Social obligatoria

\section{Variación salarial pactada}

2013

$-$

$-6,88$

$-0,19$

$-0,02$

$-0,03$

$-$

$-1,42$

$-1,69$
2014

$-2,08$

$-0,77$

$-0,87$

-
2015

$-0,13$

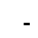

$-0,23$

Fuente: Boletín de Estadísticas Laborales. 
La segunda de las vías para reducir el salario desde una perspectiva indirecta vendría articulada a través de dos cauces, con la finalidad de reducir la jornada laboral y, por tanto, el salario de forma proporcional:

\section{A) Los expedientes de regulación de empleo: reducción de jornada y suspensión de contratos}

En buena medida por su exitosa experiencia tras su remodelación en los años 2009 y 2010, los expedientes de regulación temporal de empleo, ya sea de reducción de jornada o suspensivos, también han sido incentivados por la reforma de 2012 mediante los siguientes cambios:

1. Se procede a eliminar la autorización administrativa. No obstante, de un lado, se recabará el preceptivo informe de la Inspección de Trabajo y Seguridad Social acerca de los extremos de la comunicación y del contenido del período de consultas. En cuanto a la Autoridad Laboral, su actividad consiste en recibir la comunicación empresarial de apertura del período de consultas y dar traslado de dicha comunicación a la entidad gestora de las prestaciones por desempleo así como, en cualquier caso, ejercer un control sobre los acuerdos alcanzados para evitar el fraude en el disfrute de las prestaciones por desempleo, coacción o abuso de derecho.

2. Se elimina la anterior formulación de las causas (que simplemente remitía a aquellas "económicas, técnicas, organizativas o de producción") para adoptar la dicción marcada en el artículo 82.3 del Estatuto de los Trabajadores. Nuevamente, desaparece también cualquier referencia a la "conexión de funcionalidad", eliminándose la expresión "de la documentación obrante en el expediente se desprenda razonablemente que tal medida temporal es necesaria para la superación de una situación de carácter coyuntural de la actividad de la empresa".

3. En lo referente al procedimiento, éste será el mismo sea cual sea el número de trabajadores de la empresa y el número de afectados, regulándose por las siguientes tres reglas: i) la duración del período de consultas no será superior a 15 días; ii) se desarrollará con los representantes legales, preferentemente con las secciones sindicales; y iii) deja también de ser necesario el acuerdo con los trabajadores, pudiendo el empresario tomar la decisión de manera unilateral. 
4. Se traslada aquí el mismo régimen de impugnación que el establecido para la MSCT, si bien se mantiene la posibilidad de rechazar el acuerdo por la Autoridad Laboral a petición de la entidad gestora de prestaciones por desempleo cuando, por inexistencia de la causa motivadora de la situación legal de desempleo, el acuerdo pudiera perseguir la obtención indebida de prestaciones por parte de los trabajadores afectados.

5. Se mantienen las medidas de apoyo a la suspensión de contratos y la reducción de jornada basadas, resumidamente, en las bonificaciones del 50 por ciento en las cuotas de Seguridad Social y reposición, con el límite de 180 días, de la prestación por desempleo.

\section{Gráfico 8: Total de trabajadores afectados mensualmente por Expedientes de Regulación Temporal de Empleo, enero 2005 - febrero 2015}

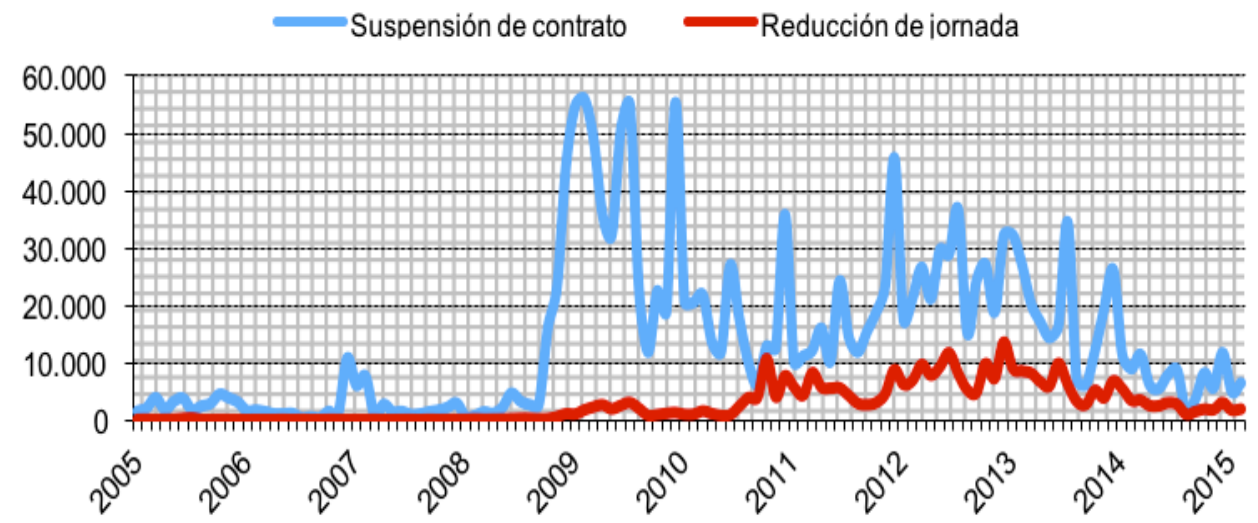

Fuente: Boletín de Estadísticas Laborales, Ministerio de Empleo y Seguridad Social.

En cuanto al uso de esta figura, se aprecia en el gráfico 8 que a partir de 2012 se produce un incremento de los trabajadores afectados por la misma, si bien ello concurre de manera paralela al empeoramiento de la situación económica, y que afecta esencialmente a las suspensiones del contrato. No obstante, este nuevo pico es inferior no sólo al del inicio de la crisis, sino también a los valores registrados al inicio de la serie histórica (1982), momento en el que comenzaban a implantarse los contratos temporales, que han funcionado también como medida de flexibilidad externa. En lo referente a las causas alegadas, destaca que las productivas rivalizan con las económicas para 
el caso de los Expedientes de Regulación de Empleo suspensivos, siendo hegemónico el caso de los de reducción de jornada, mientras que, en lo referente a la causa económica, como es lógico, es la opción de pérdidas actuales la que más peso tiene en ambos casos.

\section{B) El contrato a tiempo parcial: mecanismos de incentivos}

Finalmente, la reforma del contrato a tiempo parcial ha constituido también una de las apuestas más decididas en la reforma de 2012 (así se deduce de la exposición de motivos del Real Decreto-Ley 3/2012), dada su baja utilización en España en relación a los países de su entorno (OCDE, 2010). Ya sea para facilitar la conversión de contratos a tiempo completo o para sustituir unos por otros, esta figura ha sufrido una triple oleada de reformas desde 2012:

1. Real Decreto Ley 3/2012: se admite que, además de las horas complementarias pactadas, el trabajador a tiempo parcial pueda también realizar horas extraordinarias con el límite legal del trabajo a tiempo parcial.

2. Real Decreto Ley $16 / 2013$, de 20 de diciembre, de medidas para favorecer la contratación estable y mejorar la empleabilidad de los trabajadores:

a. Posibilidad de celebrar Contratos de Apoyo a Emprendedores a tiempo parcial.

b. Se vuelven a prohibir las horas extraordinarias, pero se habilita un nuevo régimen para la realización de horas complementarias en el que se difuminan los requisitos para su realización y aumenta cuantitativamente su número (artículos 12.5.b-e del Estatuto de los Trabajadores). Concretamente, se elimina el condicionante de que el contrato sea indefinido para que éste pueda incorporar un pacto de horas complementarias, exigiendo únicamente que la jornada de trabajo no sea inferior a 10 horas semanales en cómputo anual. De igual forma, se reduce el preaviso legal para su realización, que pasa desde los siete días anteriores a tres.

c. Se incrementan el número de contratos a tiempo parcial que pueden contener un pacto de horas complementarias.

d. Se produce la duplicación del número máximo de horas complementarias, desde el 15 por ciento al 30 por ciento de la jornada ordinaria fijada en el contrato, cifra que, 
además, en ningún caso se permite reducir por convenio - sin exigir ahora que sea sectorial-, pero sí ampliar hasta el preexistente límite del 60 por ciento.

e. Se introduce la nueva categoría de horas complementarias "de aceptación voluntaria" (únicamente pueden realizarse en el marco de contratos indefinidos a tiempo parcial con una jornada no inferior a 10 horas semanales en cómputo anual), caracterizadas por: i) no requieren un preaviso determinado; y ii) no pueden superar el 15 por ciento de la jornada ordinaria, ampliable hasta el 30 por ciento por convenio de cualquier ámbito, sin que este montante compute dentro de los límites de las horas complementarias pactadas.

3. Ley 11/2013: se amplía la posibilidad de formalizar jornadas a tiempo parcial con nuevas modalidades especiales de contratos, como el contrato a tiempo parcial con finalidad formativa, y el contrato indefinido de un joven por microempresas $y$ empresarios autónomos. Igualmente, se establecen incentivos a la contratación parcial en nuevos proyectos de emprendimiento joven.

\section{Magnitud de la devaluación salarial en términos nominales}

Si atendemos al conjunto de medidas que afectan a la reducción del salario nominal por hora trabajada, como primera aproximación es posible afirmar que dicha reducción alcanzó un máximo del 3,28 por ciento en el cuarto trimestre de 2012, habiendo recuperado su nivel inicial en el mismo trimestre de 2014 y experimentado un leve incremento del 0,75 por ciento en el primer trimestre de 2015 (gráfico 9). Sin embargo, el salario nominal total percibido por los trabajadores se ha mantenido a lo largo de todo el periodo analizado por debajo del valor correspondiente al primer trimestre del 2012, con un descenso máximo del 3,74 por ciento en el cuarto trimestre de dicho año y restando un 0,45 por ciento en el primer trimestre de 2015. A partir del año 2013 ambas variables comienzan a divergir, lo cual es el resultado del proceso de reducción del tiempo de trabajo efectivo que está experimentando la economía española en los últimos trimestres (gráfico 10). 
Sin duda alguna, a partir de la reforma del año 2012 se inició una profunda reducción del salario nominal de los trabajadores por la vía indirecta, es decir, a través del conjunto de medidas que afectan al tiempo efectivo de la jornada laboral ${ }^{5}$. De los cauces expuestos dentro de este mecanismo, este trabajo quiere destacar la evolución que ha experimentado la tasa de parcialidad en el mercado de trabajo español.

En cuanto a la utilización de esta figura laboral (gráfico 11) cabe resaltar que esta modalidad de jornada parece afianzarse ya que la tasa de parcialidad ha sufrido un fuerte incremento desde 2012, pasando de 14 a 17 puntos porcentuales, siendo especialmente intenso en 2013, si bien parece haberse frenado, a pesar del énfasis de la reforma, en torno a 2014. De forma complementaria, el gráfico 12 interpreta que la sustitución o transformación de contratos a tiempo completo por contratos a tiempo parcial ha repercutido en mayor medida - 13,1 y 14,1 por ciento respecto del total de trabajadores de cada tipo de empresa - a los trabajadores de las grandes empresas - de 250 a 499 trabajadores y de más de 499 trabajadores, respectivamente -.

\section{Gráfico 9: Evolución en España del salario nominal total por trabajador y del salario nominal por hora trabajada, 2012TI - 2015TI. 2012TI = 100}

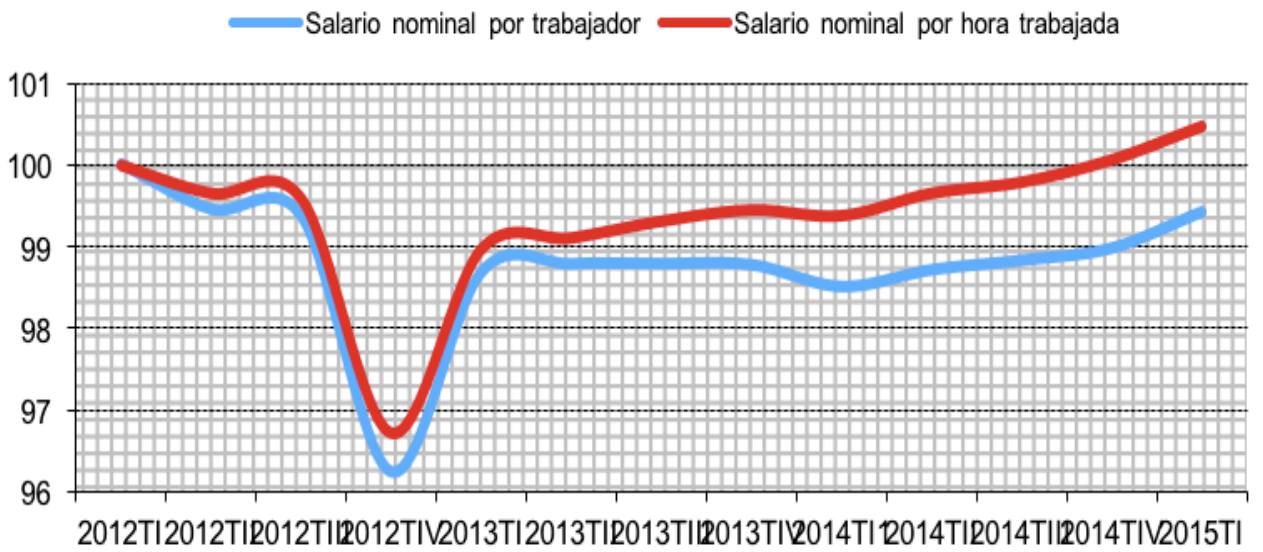

Fuente: Encuesta Trimestral de Coste Laboral, Instituto Nacional de Estadística.

\footnotetext{
5 Existen otros factores que pueden haber intervenido en la evolución negativa de los salarios - no necesariamente ligados a la reforma laboral del año 2012 - como son el aumento del desempleo desde 2008, lo cual debilita la posición negociadora de las organizaciones sindicales en los convenios colectivos, o la orientación de las políticas europeas de contención o reducción del déficit público.
} 


\section{Gráfico 10: Distribución porcentual de la reducción salarial nominal total en función del tipo de mecanismo jurídico implicado, directo o indirecto, 2012TII - 2014TIV}

口Reducción directa

口Reducción indirecta

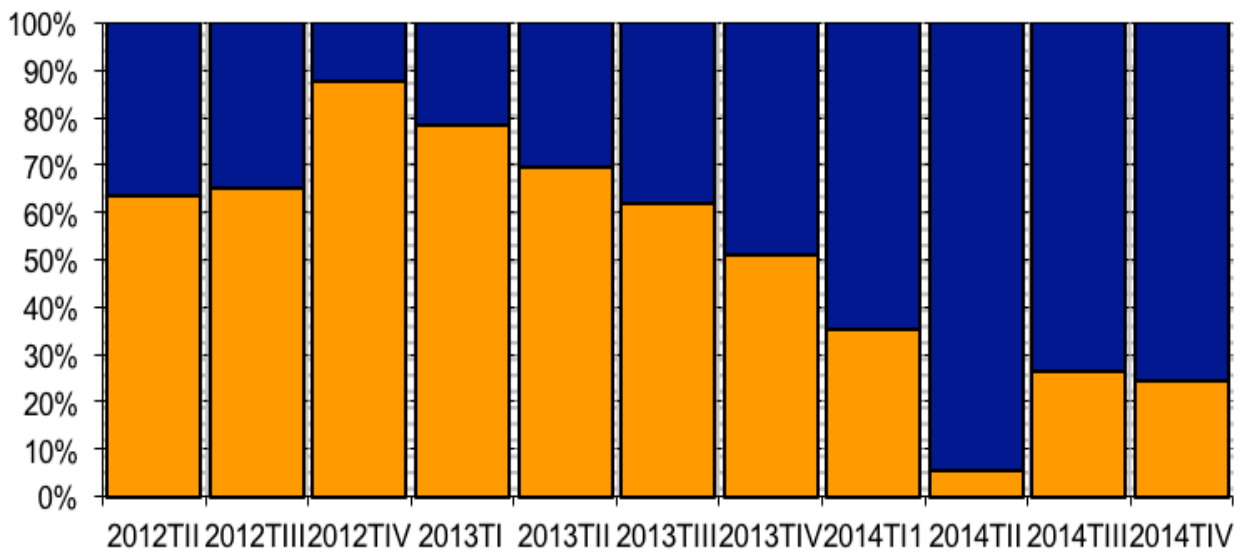

Fuente: Encuesta Trimestral de Coste Laboral, Instituto Nacional de Estadística.

Gráfico 11: Tasa de parcialidad y su tendencia ${ }^{6}, 2006 \mathrm{TI}$ - 2015TI

Tasa de parcialidad Tendencia

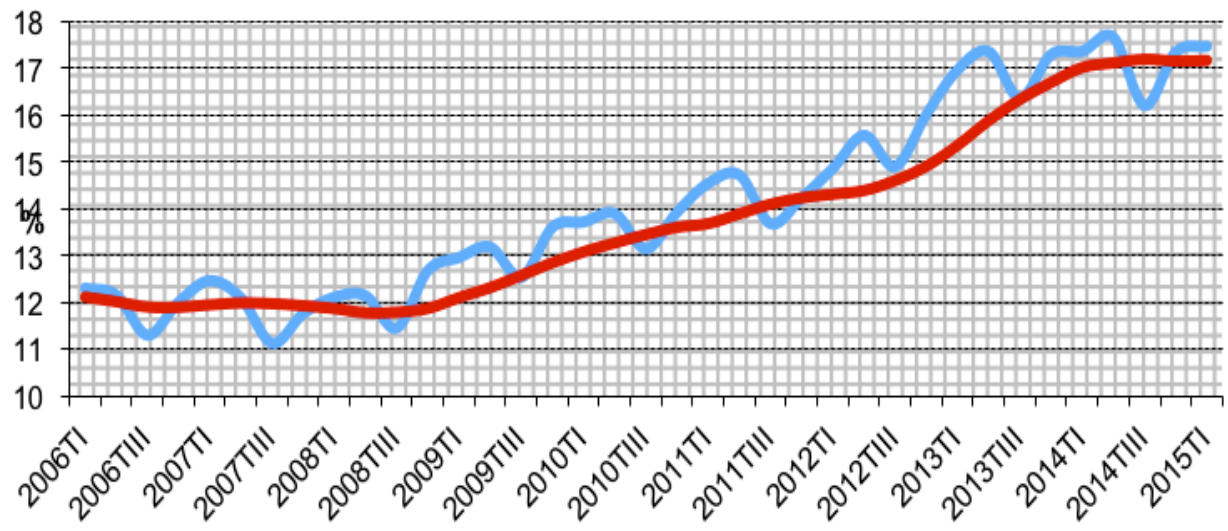

Fuente: Encuesta de Población Activa, Instituto Nacional de Estadística.

Gráfico 12: Porcentaje de empresas según el número de trabajadores que llevaron a cabo sustitución o transformación

${ }^{6} \mathrm{El}$ promedio de los 12 meses anteriores. 


\section{de contratos a tiempo completo por contratos a tiempo parcial, año 2013}

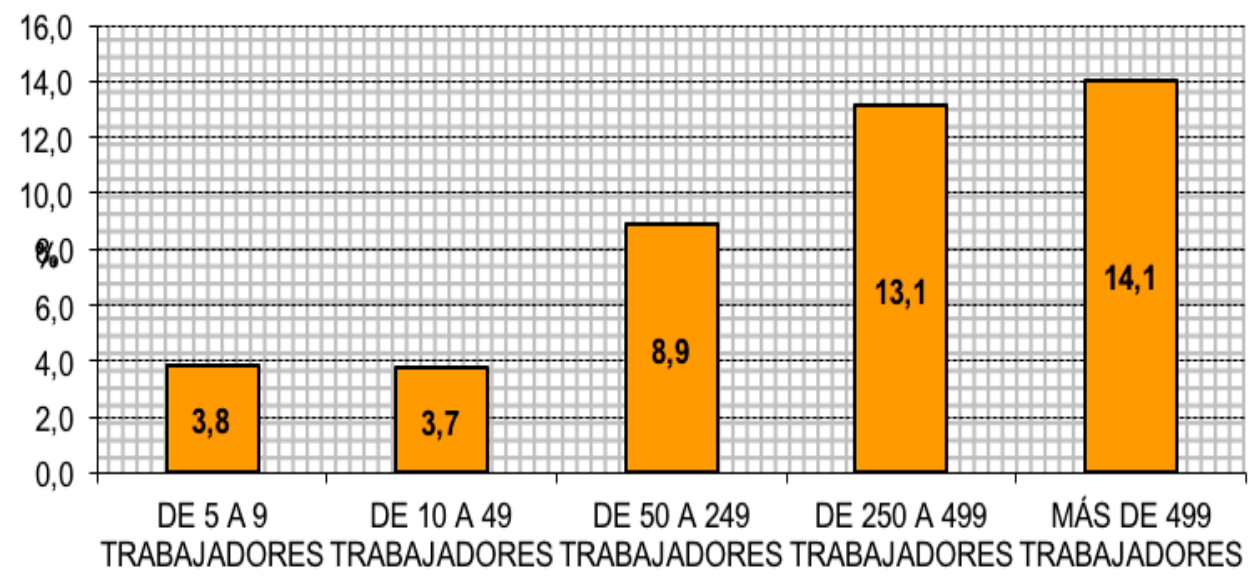

Fuente: Encuesta Anual Laboral, Ministerio de Empleo y Seguridad Social.

\section{Magnitud de la devaluación salarial en términos reales}

Una vez analizada la devaluación interna de la economía española en términos nominales y la que puede ser una de sus principales causas (el aumento de la jornada parcial), es conveniente fortalecer el análisis contemplando la evolución de los salarios en términos reales, ya que esta perspectiva nos proporcionará la verdadera magnitud de la devaluación real. Para ello, es necesario deflactar la evolución de los salarios nominales expuestos en el gráfico 9 mediante el Índice de Precios al Consumo (IPC), resultando de ello los datos que se exponen en el gráfico 13.

Tanto el salario real total por trabajador como el salario real por hora trabajada se han mantenido a lo largo de todo el periodo analizado por debajo de sus respectivos valores en el primer trimestre del año 2012. Al igual que sucedió con la evolución de los salarios nominales, el mayor descenso es el experimentado en el cuarto trimestre de dicho año, inmediatamente después de la entrada en vigor de la reforma laboral, con unas reducciones del 7,19 por ciento y del 6,73 por ciento, respectivamente. En este caso, y a diferencia de lo que sucedía con la evolución del salario nominal por hora trabajada, su homónimo en 
términos reales es un 0,83 por ciento inferior en el primer trimestre de 2015 al valor del primer trimestre de 2012 .

Más impactante aún es llevar a cabo una apertura del diafragma para conseguir situar la reforma laboral en un contexto histórico de mayor profundidad y poder así comparar la disminución del salario real con otros momentos temporales relativamente recientes. El gráfico 14 muestra cómo la reducción del salario real colocó a los trabajadores españoles en una situación muy similar a la que existía en el año 1992, lo que supone un retroceso de 20 años si tenemos en cuenta el poder adquisitivo de los que perciben un salario. La reforma laboral del 2012 se solapa con la reducción significativa que experimenta el salario real entre finales del año 2011 y principios del 2013, sin llegar a recuperar en 2014 los niveles previos a dicha reforma.

$\mathrm{Al}$ igual que se expuso en el apartado anterior, el gráfico 15 presenta la descomposición de la reducción del salario real por trabajador, en este caso en 3 componentes, que son los precios, los mecanismos jurídicos directos que reducen el salario nominal y los mecanismos jurídicos indirectos que reducen la jornada laboral. Los datos muestran que la mayor parte de la disminución del salario real corresponde en un porcentaje próximo al 70 por ciento al aumento que han experimentado los precios, siendo el 30 por ciento restante atribuible a la reforma laboral del año 2012, con una mayor participación de las medidas que han afectado a la reducción de la jornada laboral.

\section{Gráfico 13: Evolución en España del salario real total por trabajador y del salario real por hora trabajada, 2012TI - 2015TI. $2012 \mathrm{TI}=100$}

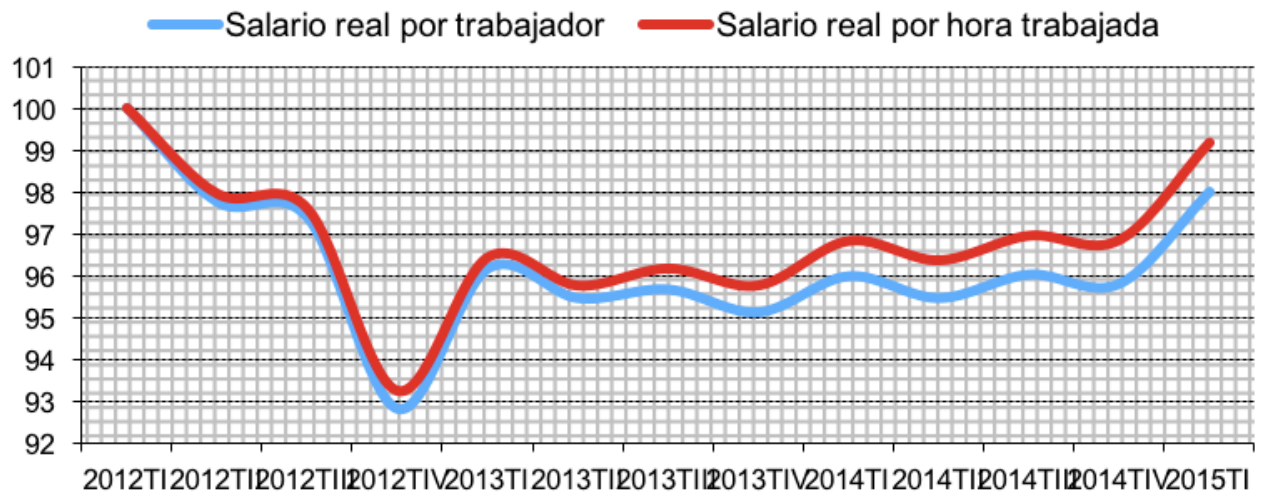

Fuente: Encuesta Trimestral de Coste Laboral e Índice de Precios al Consumo, Instituto Nacional de Estadística. 
Gráfico 14: Evolución histórica de los salarios reales por trabajador, 1992TI - 2014TIV. 1992TI = 100

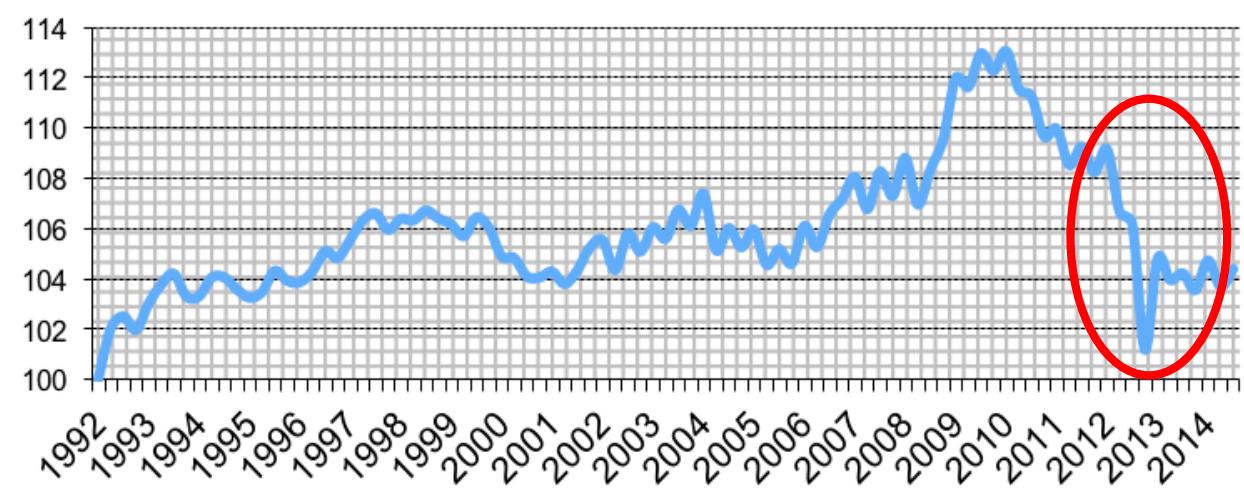

Fuente: Encuesta Trimestral de Coste Laboral, Encuesta de Salarios en la Industria y los Servicios e Índice de Precios al Consumo, Instituto Nacional de Estadística.

Gráfico 15: Distribución porcentual de la reducción salarial real en función del tipo de mecanismo jurídico implicado y de la evolución de los precios, 2012TII - 2014TIV

口Reducción directa $\quad$ Reducción indirecta $\quad$ पIPC

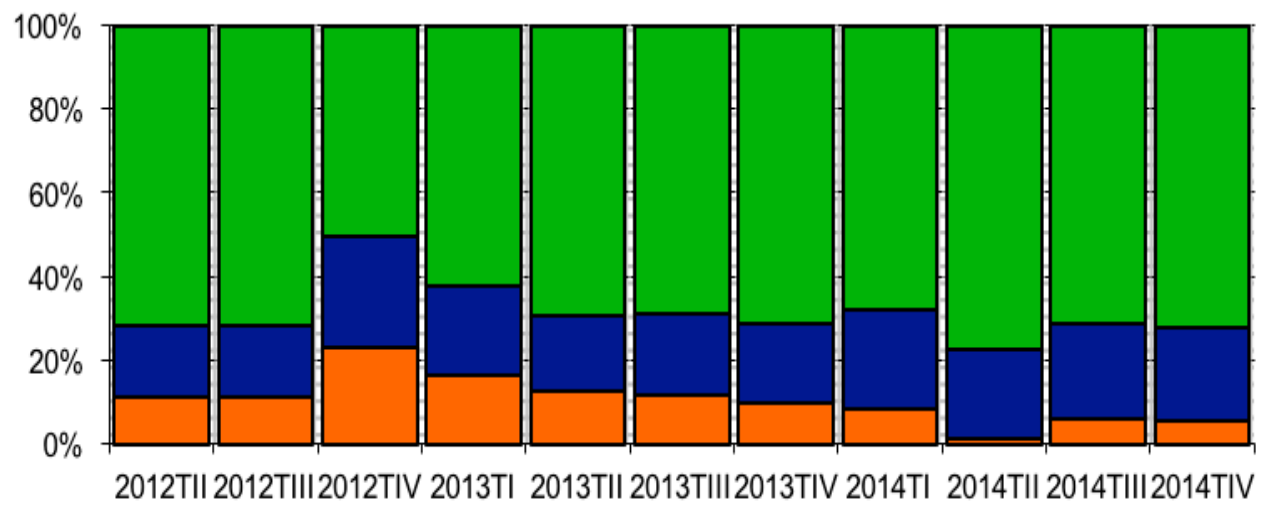

Fuente: Encuesta Trimestral de Coste Laboral e Índice de Precios al Consumo, Instituto Nacional de Estadística. 
Las disminuciones del salario nominal y del salario real mostradas en este capítulo y en el anterior eran esperadas y deseadas por instituciones económicas nacionales e internacionales. Por ejemplo, la Actualización del Plan de Estabilidad del Reino de España 2012 2015 (Gobierno de España, 2012b) decía: "Desde el lado de la oferta, el patrón de comportamiento más novedoso que contiene este escenario es la mayor flexibilidad a la baja de la remuneración salarial por trabajador. Siguiendo la estela de la deriva salarial negativa, ya observada en 2011, y con el refuerzo proporcionado por la reforma laboral de los convenios empresariales, se espera un ligero crecimiento moderado de la remuneración por trabajador en 2012, e incluso una ligera disminución en 2013. Todo ello, contribuirá junto con las mayores oportunidades de flexibilizar la organización del trabajo en las empresas, a mitigar la destrucción de empleo [...]. De esta forma, la negociación de los salarios en condiciones más competitivas, la mitigación de los mecanismos de persistencia de los salarios nominales, así como unos costes de utilización de los servicios del trabajo menos onerosos para la empresa redundarán en una menor destrucción de empleo".

También el Fondo Monetario Internacional publicaba a través de Jaumotte (2011) sus previsiones a través de las cuales se argumentaba que la implementación legal de la descentralización de la negociación colectiva conjuntamente con la flexibilidad salarial podría provocar, a medio plazo, una caída del desempleo NAIRU entre un 7 y un 10 por ciento.

E igualmente el informe del servicio de estudios del banco BBVA publicado en noviembre del año 2013 (BBVA, 2013) consideraba que una reducción de los salarios reales del 7 por ciento, es decir, que situara esta variable en los niveles del primer trimestre de 2008, produciría un aumento del empleo en una horquilla de entre el 10,4 y el 20 por ciento e, igualmente, del PIB entre un mínimo del 8,3 por ciento y un máximo del 11,6 por ciento.

Sin embargo los datos, hasta el momento, muestran una realidad muy diferente. El gráfico 16 presenta un breve resumen de la evolución que ha tenido el mercado de trabajo español en los últimos trimestres, utilizando datos que pivotan sobre el dato agregado de los tres primeros meses del año 2012, momento en el que la reforma laboral no se había puesto aún en marcha. 


\section{Gráfico 16: Evolución de los activos, inactivos, ocupados y} parados tras la reforma laboral, 2012TI - 2015TI. 2012TI $=100$

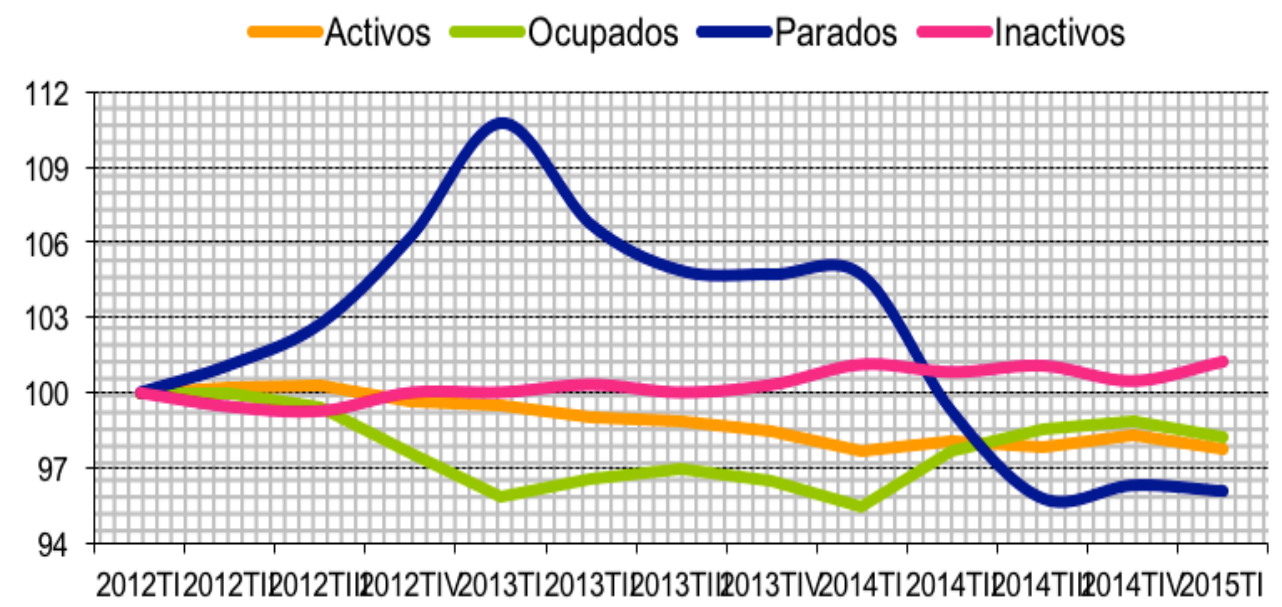

Fuente: Encuesta de Población Activa, Instituto Nacional de Estadística.

El único dato favorable es la reducción del número de parados en un 3,94 por ciento. Todo lo demás es desfavorable: el número de inactivos ha aumentado un 1,27 por ciento, el número de ocupados ha disminuido un 1,77 por ciento y el número de activos un 2,28 por ciento. De hecho, pueden aducirse dos datos adicionales para comprobar la magnitud del incumplimiento de las expectativas puestas en la reforma: en primer lugar, hasta el momento de mayor destrucción de empleo, el primer trimestre de 2014, se habían perdido 1.202 .400 puestos de trabajo con respecto al trimestre inmediatamente anterior a la entrada en vigor de la reforma; en segundo lugar, la reducción del desempleo en buena medida es achacable a que, desde la aprobación de la reforma, el mercado laboral había perdido 533.600 activos.

Por su parte, el gráfico 17 muestra la trágica situación de aquellos que desean incorporarse al mercado laboral desde la inactividad, entre ellos posiblemente muchos jóvenes que finalizan su etapa formativa. Si en el segundo trimestre de 2005 el porcentaje era 60-40 a favor de los ocupados, en el primer trimestre de 2015 esa situación se había invertido a un porcentaje de 75 - 25 a favor de los parados. En esta evolución la reforma laboral del año 2012 únicamente ha supuesto el freno a la evolución ascendente de parados y descendente de ocupados, sin que de momento parezca que se esté produciendo algún tipo de mejora en este ámbito del mercado de trabajo español. 
Y es que el desarrollo de acontecimientos que se esperaba, en su última instancia, no se ha cumplido. La relación pronosticada entre la reducción del salario nominal, y por tanto de los costes para las empresas, y el aumento de la contratación no ha llegado a producirse, habiendo pasado ya 3 años desde la puesta en marcha de la reforma laboral. Así se concluye del gráfico 18, siendo el más poblado de puntos el tercer cuadrante en el que se combina una caída de los salarios y un descenso del empleo en los sectores de actividad de la economía española entre los primeros trimestres de los años 2012 y 2015 . Es decir, la reducción de los salarios no ha generado empleo.

Y por si esto no fuera suficiente, también desde este trabajo es conveniente señalar que algunos indicadores que, a priori, han conseguido experimentar una evolución favorable, no han servido para colocar a España en una situación ventajosa con respecto a otros países de su entorno. Este es el caso de las exportaciones españolas, que entre el primer trimestre de 2012 y el cuarto trimestre de 2014 han experimentado un crecimiento del 11,33 por ciento (13,01 por ciento para las exportaciones de bienes y 7,36 por ciento para las exportaciones de servicios), pasando a suponer del 29,82 al 32,42 por ciento del Producto Interior Bruto español durante el mismo periodo. Dicho comportamiento, teóricamente, estaría vinculado a una hipotética mejora de la competitividad en precios de la economía española fruto de la reducción de los costes laborales, los cuales han disminuido desde el primer trimestre de 2012 un 2,68 por ciento en términos nominales y un 5,8 por ciento en términos reales.

Para corroborar si existe una relación de causalidad entre la reducción de los costes laborales unitarios y la exitosa evolución de las exportaciones españolas vía reducción de precios ${ }^{7}$ es necesario acudir a los denominados "Índices de competitividad de la economía española" elaborados por el Ministerio de Economía y Competitividad.

\footnotetext{
7 Esta es al visión que se plasma en el Informe de Evaluación del Impacto de la Reforma Laboral elaborado por el Ministerio de Empleo y Seguridad Social (2013). Concretamente, se señala que "La reforma laboral, con medidas que han promovido un mayor recurso a mecanismos de flexibilidad interna y la dinamización de la negociación colectiva, ha conseguido incrementar la competitividad de la economía [...]. La mejora de la competitividad ha permitido que las exportaciones españolas hayan demostrado su gran capacidad y dinamismo, incluso en un contexto de crisis internacional".
} 
Gráfico 17: Distribución porcentual de la evolución del destino de los trabajadores que pasan de la inactividad al mercado de trabajo, 2005TII - 2015TI

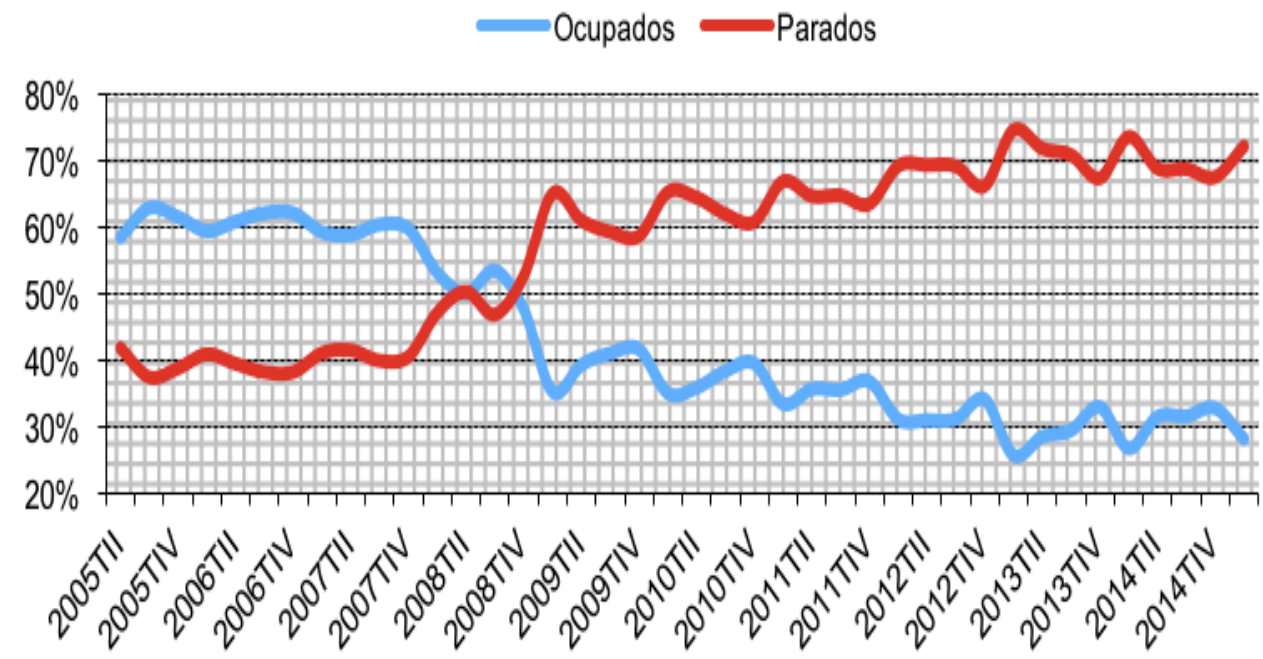

Fuente: Encuesta de Flujos de Población Activa, Instituto Nacional de Estadística.

Gráfico 18: Relación entre la tasa de variación salarial real (eje W) y la tasa de variación del empleo por sectores de actividad ${ }^{8}$ (eje L), 2012TI y 2015TI

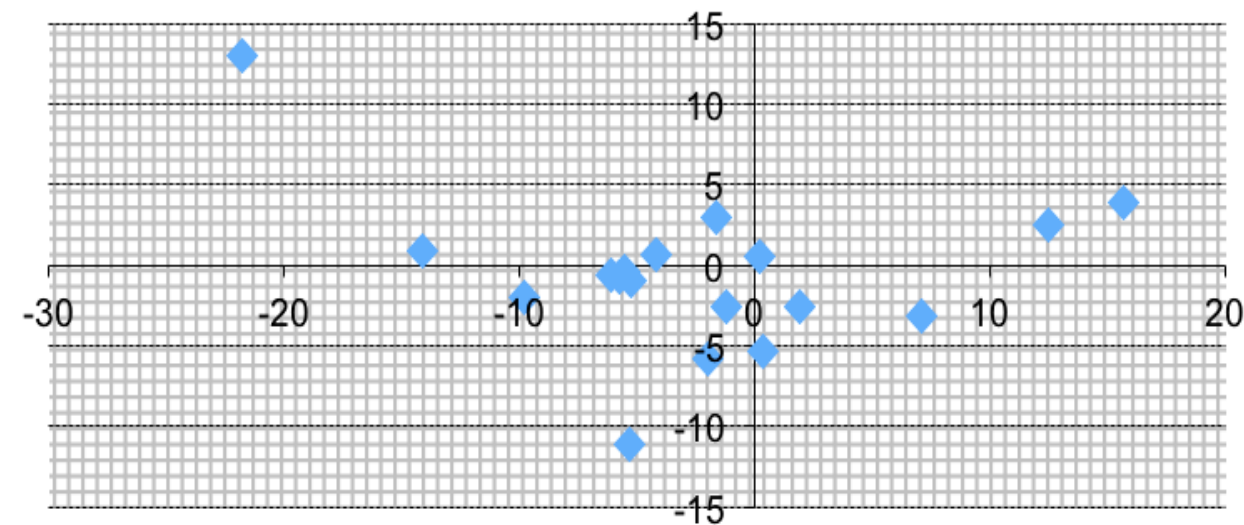

Fuente: Encuesta de Población Activa, Encuesta Trimestral de Coste Laboral e Índice de Precios al Consumo, Instituto Nacional de Estadística.

8 Desde Industrias extractivas (B) a Otros Servicios (T), siguiendo la Clasificación Nacional de Actividades Económicas CNAE - 2012. 
Gráfico 19: Posición competitiva española a través del Índice de Precios al Consumo, enero 2012 - mayo 2015. Enero $2012=100$

IPC RELATIVO EN MONEDA NACIONAL DE ESPAÑA FRENTE A LA UNION EUROPA (UE 27)

IPC RELATIVO EN MONEDA NACIONAL ESPAÑA FRENTE A PAISES DESARROLLADOS

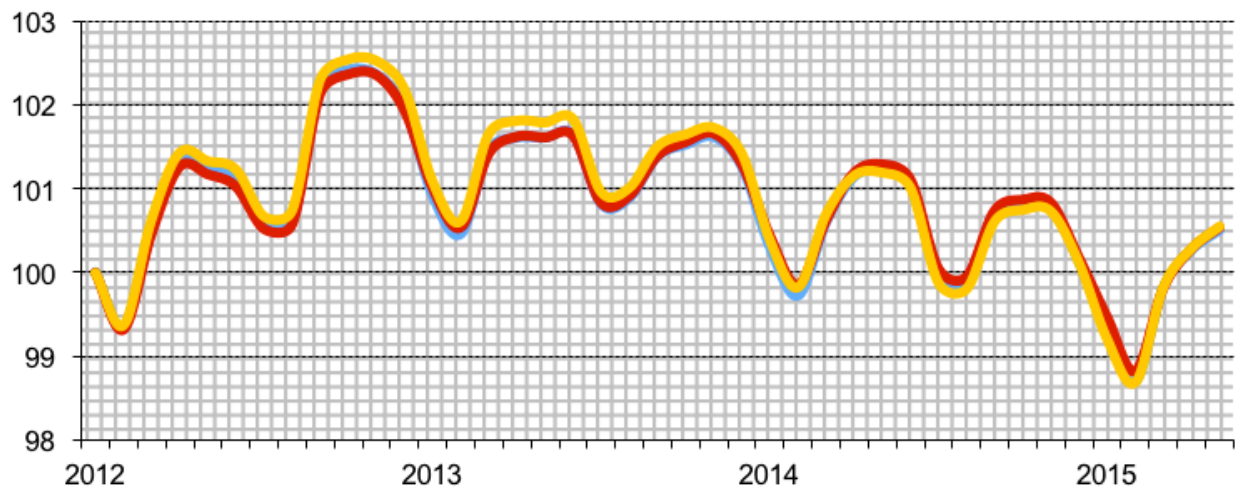

Fuente: Dirección General de Análisis Macroeconómico y Economía Internacional, Ministerio de Economía y Competitividad.

\section{Gráfico 20: Posición competitiva española a través del Índice de} Precios Industriales, enero 2012 - abril 2015. Enero $2012=100$

IPRI RELATIVO EN MONEDA NACIONAL DE ESPAÑA FRENTE A LA UNION EUROPA (UE 27)

—IPRI RELATIVO DE ESPAÑA FRENTE A LA ZONA EURO

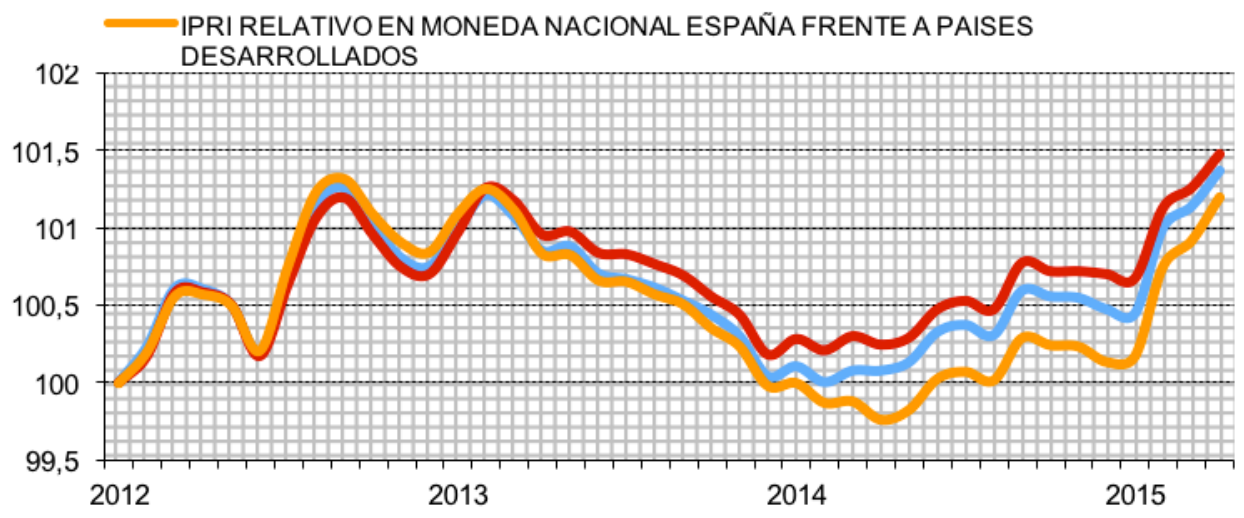

Fuente: Dirección General de Análisis Macroeconómico y Economía Internacional, Ministerio de Economía y Competitividad. 
A través de los datos presentados en los gráficos 19 y 20, y tomando como referencia el nivel en el que éstos indicadores se encontraban al principio del año 2012, tanto a nivel de precios al consumo (IPC) como de precios industriales (IPRI) se aprecia cómo la economía española no ha experimentado una ganancia de competitividad en términos comparativos con el valor correspondiente a enero del año $2012^{9}$.

El motivo por el cual las exportaciones aumentaron no estaría entonces vinculado a la reforma laboral y a la reducción de los costes laborales, sino que más bien se relaciona con el argumento que se cita en Fernández (2014): "En suma, en el conjunto del periodo comprendido entre 2009 y 2013 se produjo una mínima ganancia de competitividad en precios, que resultó de la depreciación del euro, no de una reducción de los precios, los cuales, por el contrario, aumentaron; es decir, los exportadores españoles aprovecharon la devaluación del euro para elevar sus precios algo más que los de sus competidores, de modo que apenas se logra una ganancia de competitividad en precios".

Por tanto, la gran mayoría de las empresas han utilizado la reducción de costes salariales para incrementar sus márgenes de beneficio en lugar de procurar una ganancia de competitividad (Paul y Uxó, 2014), lo cual, al haberse producido paralelamente al crecimiento de las exportaciones, viene a confirmar lo que se denomina como la "paradoja de Kaldor"10.

\section{Causas de la contradicción objetivos-resultados}

¿Qué ha sucedido? ¿Por qué existe tal disfunción entre objetivos y resultados?

Del análisis hasta ahora realizado se ha podido comprobar que, aunque la política de devaluación salarial parecía estar sustentada sobre una lógica teórico - económica coherente que, además, encontraba encaje con el relato histórico sobre la dinámica salarial en España durante los últimos años, los efectos producidos por la misma, sin embargo, son diametralmente opuestos a los previstos desde esa perspectiva analítica, en parte tal vez porque algunos de los razonamientos apriorísticos establecidos por la corriente ortodoxa, junto

\footnotetext{
${ }^{9}$ La reducción de la serie implica mejoría en la competivididad - precio de la economía.

10 Para una explicación detallada de esta dinámica véase Maroto et al. (2008) y Álvarez y Luengo (2011).
} 
a la cual estaban las administraciones públicas y algunos organismos nacionales e internacionales, no eran del todo exactos. Desde este trabajo se propone una reflexión sobre dos cuestiones que en cierto sentido motivaron la reforma laboral: la espiral precios - salarios y la asimetría entre los salarios y el ciclo económico.

En relación a la espiral precios - salarios y los supuestos efectos anticompetitivos de la misma, la realidad de los datos no corrobora la visión que la reforma toma de esta dinámica. Atendiendo a los datos de Eurostat, el gráfico 21 muestra cómo la cuota de las exportaciones españolas en los países de la OCDE creció entre 1999 y 2008 un 9,7 por ciento, mientras que otras potencias comerciales como Estados Unidos o Francia, que sufrieron crecimientos de los costes laborales muy inferiores a los de España, perdían un 19,3 y un 14,1 por ciento, respectivamente, y otras como Italia, Reino Unido o Japón a duras penas conseguían mantener la cuota del año 1999. Es significativo que en el año 2009 el dato español únicamente era superado por el país germano.

\section{Gráfico 21: Cuota de mercado de las exportaciones para varios} países en el comercio de la OCDE, 1999 - 2013. 1999 = 100

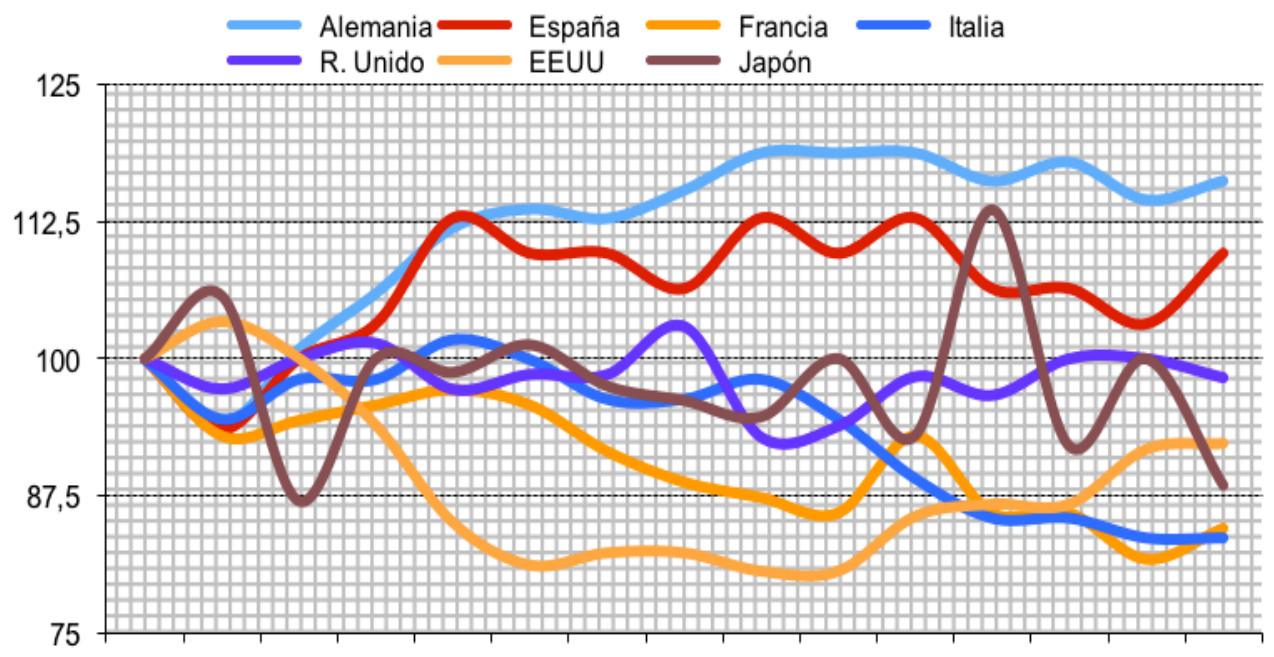

199920002001200220032004200520062007200820092010201120122013

Fuente: Eurostat. 
Por tanto, este comportamiento comparativamente más positivo de las exportaciones españolas en relación a los países de su entorno rompería el vínculo conceptual, al menos en la intensidad con la que venía siendo afirmado, entre regulación laboral, crecimiento salarial, incremento de precios y reducción de la competitividad internacional, quedando ésta determinada por otros factores como por ejemplo las características de la estructura productiva, la falta de competencia en los mercados de producto, el tamaño de las empresas o la dependencia tecnológica (paradoja de Kaldor).

En cuanto a la supuesta asimetría entre los salarios y el ciclo económico previa a la reforma laboral, el gráfico 22 lleva a cabo el siguiente experimento para el periodo comprendido entre los años 2008 y 2012: en la parte de la izquierda se compara el incremento pactado de los salarios (ordenadas) con la evolución del empleo (abscisas) en cada sector de actividad; en la parte de la derecha se contrasta la relación entre la evolución de la producción (ordenadas) y la evolución del empleo (abscisas) también en cada sector de actividad. Si la asimetría fuera cierta, lo que debería aparecer sería una relación inversa en la parte izquierda y una relación directa en la parte derecha. De esta forma se podría concluir que cuanto mayor es el salario pactado, menor es el número de asalariados, y que cuanto menor es el número de asalariados, menor es la producción de la economía, obteniendo de esta forma que cuanto más crecen los salarios menos se produce, pudiendo justificar así la necesidad de una reducción salarial en términos nominales y reales con el objetivo de aumentar la producción $\mathrm{y}$, posteriormente, el empleo.

Los datos no resultan del todo concluyentes en esta dirección. En cuanto a los gráficos de la parte izquierda, la relación negativa no es evidente. De hecho, si se calcula la media del coeficiente de correlación entre la variación del salario y del empleo en los cinco años previos a la reforma laboral, el dato obtenido es -0,055, es decir, no se puede concluir que exista una correlación ni negativa ni positiva entre ambas variables. Por lo que se refiere a los gráficos de la derecha, es decir, los que relacionan la producción con el empleo, a priori parece existir una relación positiva entre ambas variables; sin embargo, la media de los coeficientes de correlación de los cinco años estudiados es de 0,399 por lo que no se puede determinar que la relación directa entre ambas variables sea consistente en cuanto a su intensidad. 
Gráfico 22: Relación entre la evolución del incremento salarial pactado en la negociación colectiva (W) y el empleo (L) (izquierda), y entre la evolución de la producción (Y) y el empleo (L) (derecha), por sectores de actividad, $2008-2012$
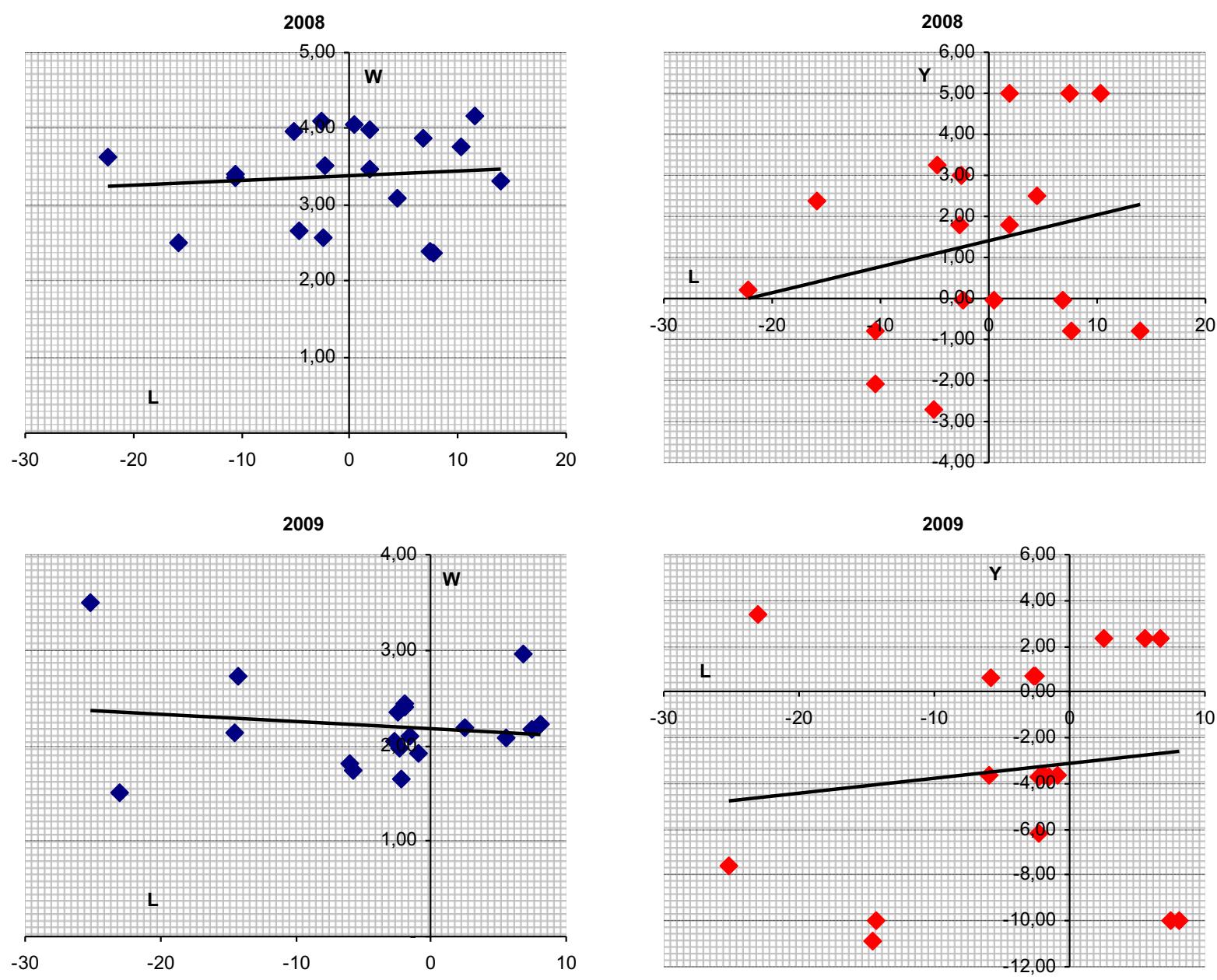


\section{Gráfico 22 (continuación)}
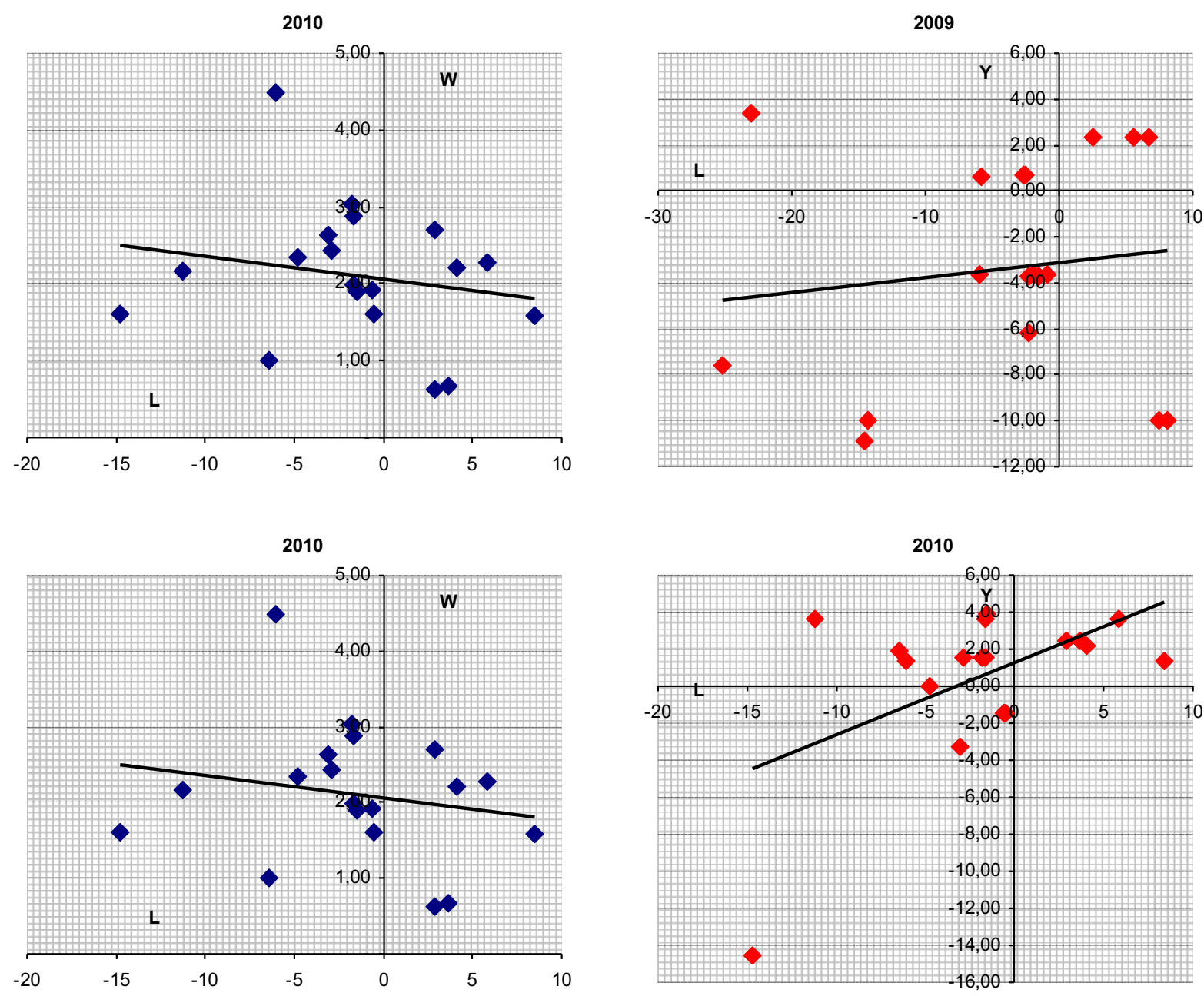


\section{Gráfico 22 (continuación)}
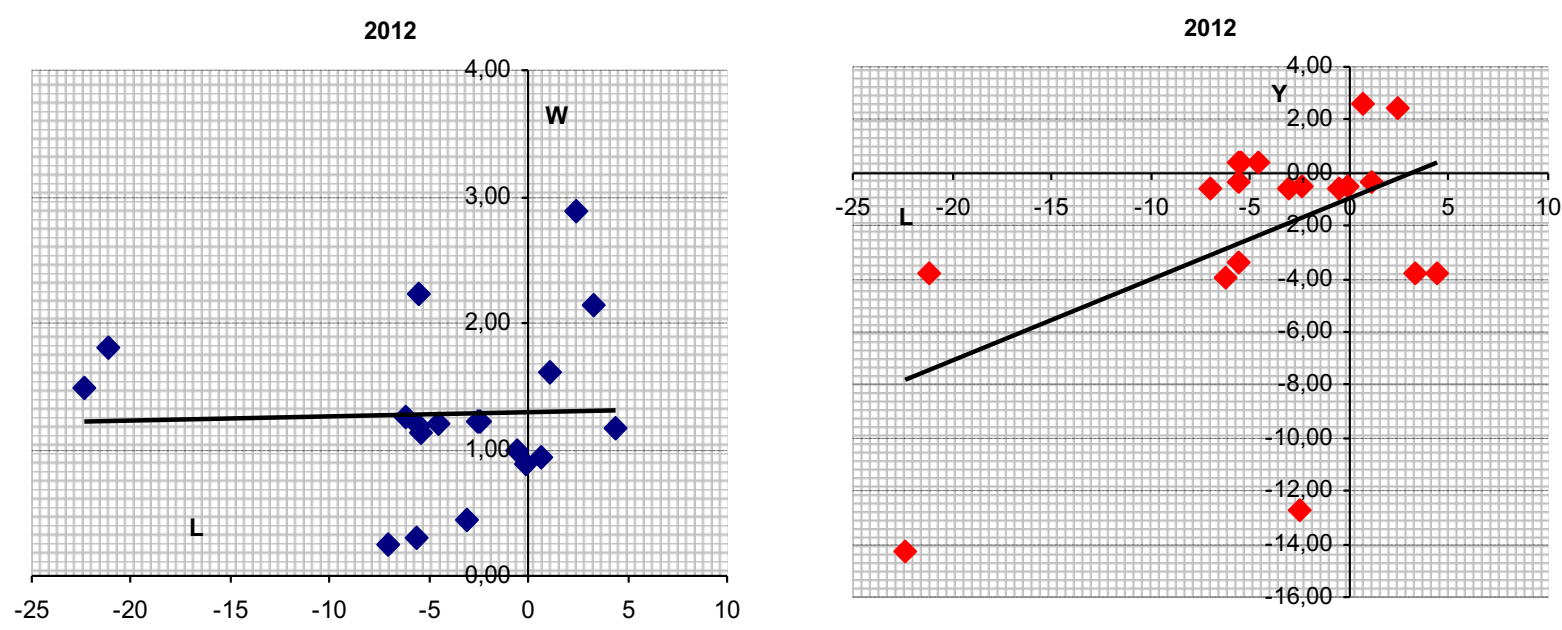

Fuente: Boletín de Estadísticas Laborales, Ministerio de Empleo y Seguridad Social; Contabilidad Nacional de España y Encuesta de Población Activa, Instituto Nacional de Estadística.

Como conclusión, aunque las dinámicas planteadas por el paradigma ortodoxo existen, tienen parte de responsabilidad en el incremento del desempleo $\mathrm{y}$, efectivamente, están parcialmente originadas por desajustes e inercias regulatorias, no parecen haber generado los efectos que el sustento teórico de la reforma laboral les atribuye tanto sobre la competitividad como sobre la destrucción del empleo. Por tanto, existe en el diagnóstico sobre el cual la reforma configura sus medidas a aplicar un primer error de profundidad en la interpretación de las variables salariales, comerciales y de precios que implica una desconexión entre las prescripciones derivadas de aquél y la realidad de las causas, efectos y características de los problemas sociolaborales.

No obstante, se hace necesario concluir este artículo con alguna explicación en cuanto a porqué la reforma, a pesar de la aparente coherencia de su lógica interna, genera unos efectos contrarios a los previsibles, lo cual se abordará en la siguiente sección. 


\section{La economía del salario desde una óptica alternativa a la Teoría Neoclásica}

A efectos de explicar con un mayor grado de profundidad los motivos por los que la devaluación salarial no ha generado los efectos previstos sobre el empleo, es posible utilizar el denominado enfoque postkeynesiano - institucionalista (Piore, 1983; Lavoie, 2014), caracterizado porque la demanda de trabajo no depende de la productividad marginal del trabajo sino de la evolución de la demanda agregada total, es decir, como si fuera una "demanda derivada".

De este modo, dicho esquema rechaza el papel del salario como mecanismo equilibrador del mercado de trabajo a través de fundamentos microeconómicos, así como enfatiza en la importancia de la distribución social del ingreso entre salarios y beneficios para la determinación del empleo, ya que cada grupo social posee propensiones marginales al consumo y al ahorro diferentes que, no obstante, impactan en la demanda agregada total (Lavoie, 2014).

Sobre estas bases, el juicio de eficiencia que este modelo realiza se centra en dos elementos: 1) Su capacidad para afectar positiva o negativamente a la demanda agregada; y 2) suponer o no un elemento obstaculizador/facilitador o amortiguador/amplificador de la traslación demanda agregada-demanda laboral (donde, excepcionalmente, puede encontrar algunos elementos en común con el enfoque ortodoxo).

Se trata de un modelo que conecta con la conocida expresión del profesor Luis Toharia (Toharia, 2011): "El mercado de trabajo ni crea ni destruye empleo, lo que hace es transmitir al empleo la evolución de los mercados de productos. Ese «mecanismo de transmisión» puede funcionar mejor o peor, desde luego, pero para saberlo no basta con mirar a los resultados del empleo y el paro sino que hay que ver de dónde proceden las perturbaciones y si el mercado de trabajo está transmitiendo correcta o incorrectamente esas perturbaciones".

Tomando la primera de las perspectivas, y siempre manteniendo la demanda de trabajo como demanda derivada de la demanda agregada global, se entiende que el mercado de bienes y servicios y el mercado de trabajo son interdependientes, correspondiendo entonces analizar qué papel juega el salario (y las instituciones jurídicas que lo determinan) en la demanda agregada y, por tanto, determinar en qué punto la concepción del salario como renta prepondera o se equilibra con la del salario como coste, y viceversa (Dejuán, 1992). En términos formales, puede elaborarse un modelo en el que se relaciona la evolución de los salarios con la inversión, y el incentivo a ésta por un 
mayor consumo o el desincentivo a la misma por incurrirse en sobrecostes salariales ${ }^{11}$. Así, la función de inversión puede formularse como producto de dos funciones independientes, a saber:

$$
I=I_{d} * I_{g}
$$

en la que, por un lado, $I_{d}$ representa el efecto positivo de un aumento salarial derivado de que el mismo implica un aumento proporcional de la renta del trabajo dependiente y, por tanto, de los gastos en consumo, del grado de utilización de la capacidad productiva, de los beneficios totales y, así, del beneficio esperado; por el otro, $I_{g}$ representa el efecto de un incremento del coste medio del trabajo por unidad de producto que tiende a hacer disminuir el margen sobre los precios y, por tanto, el beneficio. Por tanto, la tasa de variación de las inversiones por unidad de tiempo puede escribirse como la suma de:

$$
\hat{I}=\hat{I}_{d}+\hat{I}_{g}
$$

Las condiciones indicadas son satisfechas por las curvas exponenciales reflejadas por la figura 1 donde la tasa variación de los salarios por unidad de tiempo viene representada por $\hat{S}$. Según esto, $\hat{I}_{g}$ y $\hat{S}$ se relacionan de forma inversa, y $\hat{I}_{d}$ y $\hat{S}$ se relacionan de forma directa. Cuando $\hat{S}$ es cero, $\hat{I}_{g}$ es positivo ya que la tasa de variación de la productividad es positiva; cuando $\hat{S}$ es cero, $\hat{I}_{d}$ también es cero ya que $\hat{S}$ es la única fuente de demanda de bienes de consumo.

La tasa óptima de variación de los salarios $\widehat{S_{0}}$ se consigue en el punto en el que las pendientes en valor absoluto de $\hat{I}_{d}$ y de $\hat{I}_{g}$ son iguales, lo cual se alcanza en el punto en el cual:

$$
\left|\frac{d \hat{I}_{d}}{d \hat{S}}\right|=\left|\frac{d \hat{I}_{g}}{d \hat{S}}\right|
$$

11 El desarrollo formal que se expone a continuación está íntegramente extractado de Sylos-Labini (1988). En este modelo se considera que la tasa de aumento de la productividad está determinada exógenamente y que es constante así como que los salarios son la única fuente para la demanda de bienes de consumo. Una versión literal de un planteamiento similar que, incluso, profundiza con mayor riqueza en muchos de los elementos aquí presentados, puede encontrarse en Muñoz de Bustillo (1993). 
Figura 1: Relación entre la tasa de variación de la inversión y la tasa de variación de los salarios, efecto salario - coste y salario renta

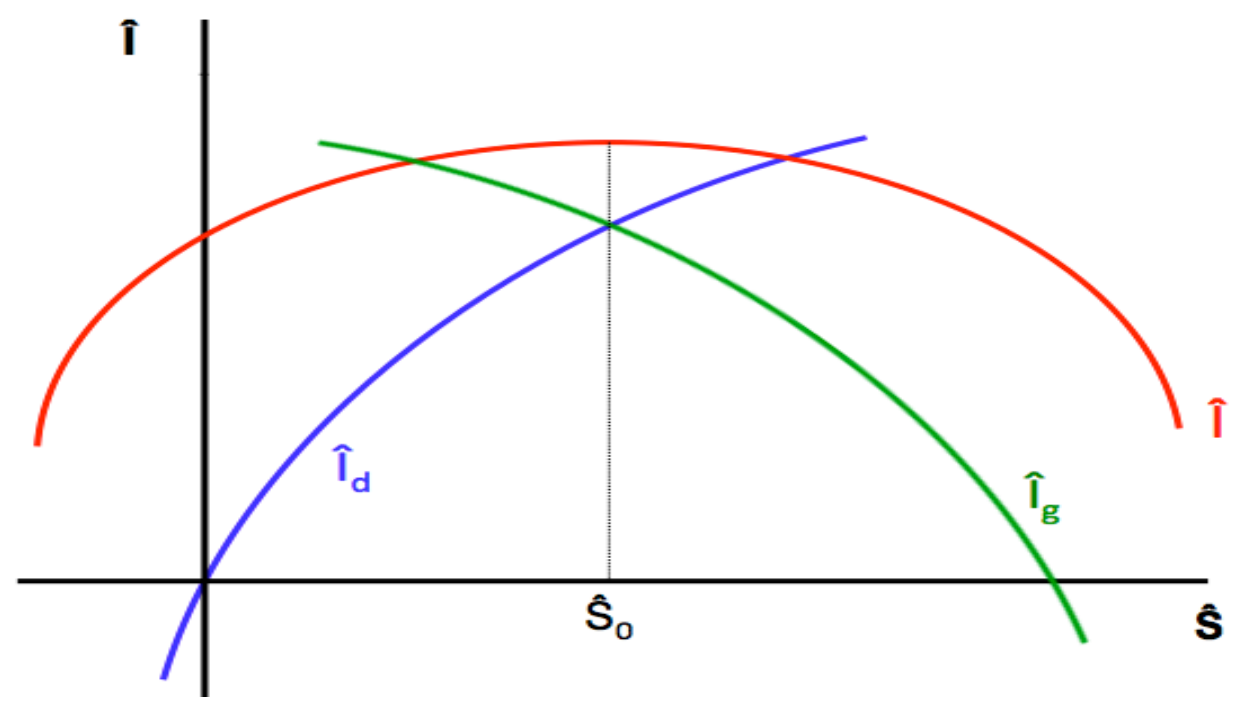

Fuente: Sylos - Labini, 1988.

De este análisis teórico se deriva que, dado el aumento de la productividad, hay una tasa "óptima" de evolución de los salarios, es decir, una tasa que hace máximos los efectos positivos y mínimo los negativos sobre las inversiones. Esta óptica, que no es otra que la manifestación de la metodología realista - empirista de este paradigma, junto a la inserción del tiempo histórico como principio rector, frente al tiempo lógico y mecánico neoclásico, ha llevado a la diferenciación en términos estáticos entre países cuya estructura económica está basada o bien en las ganancias (profit - led) en las que predomina el efecto salario - coste, o bien en los salarios (wage - led) en las que prepondera el efecto salario - renta (Bhaduri y Marglin, 1994; Naastepad y Storms, 2006; Stockhammer, Onaran y Ederer, 2009; Stockhammer, 2011).

A partir de este modelo surge lo que se conoce como la "paradoja de los costes": si bien es cierto que cada empresa tomada individualmente lograría más beneficios si consiguiera bajar sus costes mediante una reducción salarial, si todas las empresas consiguen rebajar los salarios mientras aumentan el margen de beneficios al conservar los precios a un nivel fijo, el desplome del poder adquisitivo de la masa laboral llevará a que las empresas en su conjunto vendan menos productos, pasando entonces a reducirse sus beneficios (Kalecki, 
1966; Lavoie, 1992, Dejuán, 1996). De este modo, la disminución del salario real llevaría inicialmente a una subida del margen de beneficios por unidad vendida, pero la masa del excedente total no cambia, de modo que la renta nacional, las ventas y el empleo global disminuyen, reduciéndose la demanda global como consecuencia del cambio en el reparto de los ingresos en detrimento de los asalariados, que poseen una propensión marginal al consumo superior.

Si trasladamos este razonamiento a la realidad de los datos oficiales encontramos un consistente grado de evidencia empírica al respecto. En el gráfico 23 se observa cómo el gasto total de las familias se desploma un 5,34 y un 8,88 por ciento entre 2011 y 2013 , en términos nominales y reales, respectivamente. De igual forma se concluye que es mucho más profunda la caída real del gasto, como consecuencia del aumento de los precios: por ejemplo, de 2010 a 2011 existió una recuperación en términos nominales que no se produjo si el gasto es deflactado.

El gráfico 24, tal y como prevé la Teoría Post-keynesiana, muestra que la reducción de los salarios reales solo incrementa durante un breve espacio de tiempo el grueso de los beneficios empresariales (el año 2012), pues al mantenerse o incrementarse los márgenes de beneficio mediante el mantenimiento o el incremento de los precios de manera correlativa a la reducción de los costes laborales, no tarda en notarse en los propios beneficios empresariales la incapacidad de los asalariados de adquirir los niveles de producción que venían siendo consumidos, volviendo entonces a erosionarse los beneficios empresariales, pero habiéndose destruido por el camino sustanciales cotas de empleo.

Por último, y con el objetivo de cerrar el análisis resolviendo cuestiones que han sido previamente establecidas, la propia idea de generar una "espiral precios - salarios" negativa constituye una propuesta sumamente peligrosa para una economía como la española. En este punto teorizaba el enfoque ortodoxo que la posterior caída de precios, tras la inicial deflación salarial, producía un incremento de la demanda agregada por la revalorización de los ahorros preexistentes ("efecto Pigou") y por la caída de los tipos de interés, ante el exceso de fondos prestables, mediante la cual se intentaba incentivar la petición de créditos ("efecto saldos reales"). Sin embargo, este planteamiento es erróneo por las cuestiones siguientes: 


\section{Gráfico 23: Evolución del gasto total de las familias en términos nominales y reales, $2008-2014$}

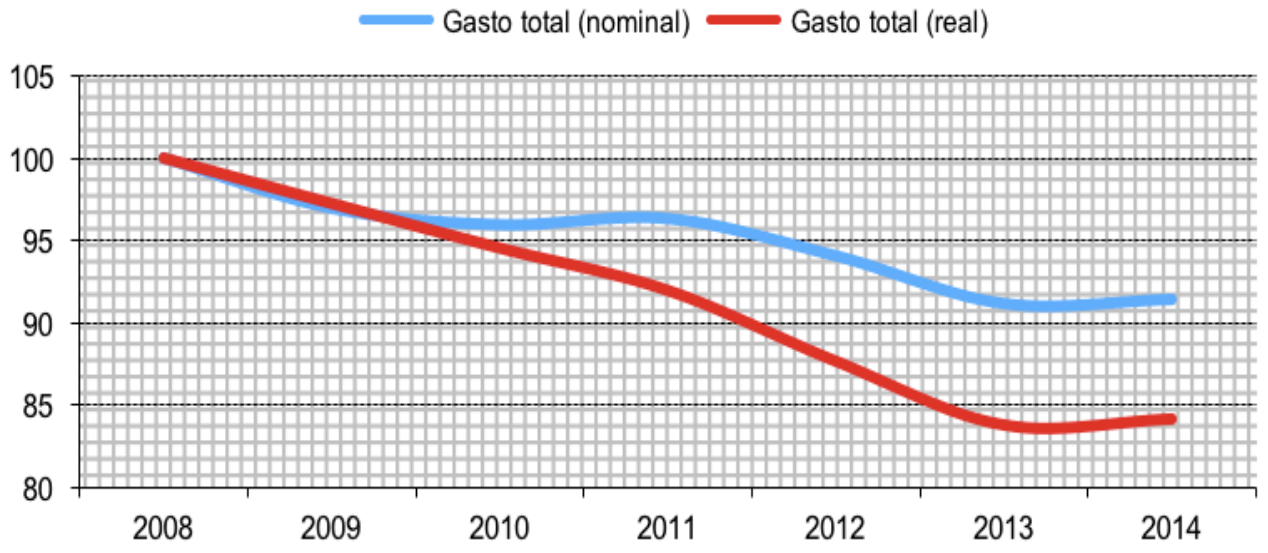

Fuente: Encuesta de Presupuestos Familiares, Instituto Nacional de Estadística.

\section{Gráfico 24: Evolución del excedente bruto de explotación y del salario real por trabajador, 2012TI - 2015TI. 2012 TI = 100}

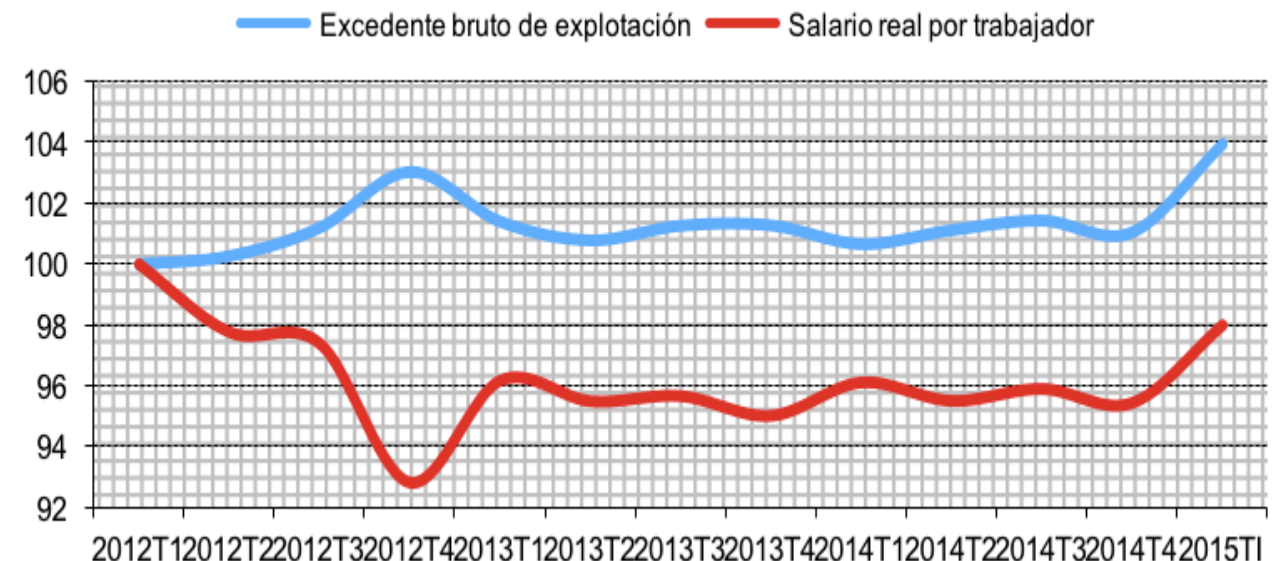

Fuente: Contabilidad Nacional Española, Encuesta Trimestral de Costes Laborales e Índice de Precios al Consumo, Instituto Nacional de Estadística.

Para que el "efecto saldo real" funcionara efectivamente, la totalidad de la oferta monetaria de la economía debería estar determinada exógenamente. Sin embargo, buena parte del dinero de la economía está constituido por el activo del sector privado, que tiene 
como contrapartida el mismo pasivo del sector privado (créditos que éste ha recibido), de modo que debe ser considerado como endógenamente determinado por la propia actividad económica (López, 2009). Así, un menor nivel de salarios determina una menor demanda de capital y trabajo por parte de los empresarios (y una menor demanda de dinero por motivo transacción por parte de los trabajadores), y menores depósitos derivados de la menor cantidad de créditos que genera la caída en la demanda de dinero. Por tanto, la oferta monetaria se moverá en la misma dirección que los salarios, dejando inalterado el nivel de saldos reales y la tasa de interés, sin importar cuán flexibles sean los salarios.

En relación al "efecto Pigou", para los postkeynesianos la deflación de precios y salarios induce, no sólo a un aumento del valor real del ahorro preexistente, sino también a un aumento del coste real de endeudamiento (Panigo, 2006), pues el hecho de que las empresas se vean obligadas a reducir sus precios nominales ante el menor consumo, mientras el valor nominal de las deudas adquiridas se mantiene, les obliga a realizar una cantidad adicional de ventas para poder saldar las mismas, de modo que, en términos reales, el endeudamiento se agravará como consecuencia de esta política, y ello en un contexto en el que la reducción de la demanda disminuye las ventas que las empresas realizan. Lo mismo puede señalarse del endeudamiento de las familias, obligadas a ganar un mayor número de salarios para poder saldar las sus deudas. Ello supone, a su vez, que los agentes intentan incrementar sus tenencias monetarias, reduciendo la velocidad de circulación del dinero, lo cual potencia el efecto depresivo sobre la demanda agregada (Tomás, 1992). Por tanto, el "efecto Pigou" solo sería válido para economías carentes de un endeudamiento considerable y poseedoras de altas tenencias de ahorros, caso en el cual la revalorización de éstos superaría a la de las deudas, pero no en una economía fuertemente endeudada como la economía española. Incluso, las expectativas de salarios y precios más bajos en el futuro llevan a una sustitución intertemporal del consumo y la inversión desde el presente hacía el futuro, reduciéndose así la demanda agregada actual de manera adicional.

\section{Conclusiones}

Uno de los grandes estudiosos (si no el que más) de las reformas laborales que se han llevado a cabo en España (Cebrián, Moreno y Pérez Infante, 2013), el profesor Luis Toharia, nos dejó algunos 
comentarios y reflexiones sobre las cambios normativos que se han llevado a cabo en el pasado y que, como en este trabajo se ha podido comprobar, aún tienen plena vigencia y pueden ser perfectamente implementados sobre la reforma laboral del año 2012.

Por una parte, planteaba que "normalmente, los únicos efectos grandes que suelen tener los cambios normativos del mercado de trabajo son precisamente aquellos que nadie previó, como la gran extensión de los contratos temporales a partir de la reforma de 1984 o el impacto en el nivel y la distribución de los despidos que provocó la reforma de 2002".

Por otro lado, Luis Toharia mantenía que, "como norma general, cualquier reforma laboral debería crear menos problemas que los que soluciona", y que "tampoco pueden esperarse cambios cruciales y rápidos gracias a modificaciones de la regulación legal. El que la regulación del mercado de trabajo pueda alterarse con cierta velocidad frente a otros instrumentos no puede equipararse a que los efectos sean inmediatos y grandes ya que los distintos agentes sociales y, en concreto, las empresas y los trabajadores usan la normativa legal de forma estratégica en la persecución de sus propios intereses y que, por tanto, aprovecharán (cada uno según su capacidad de poder en el conjunto de las relaciones laborales) cualquier resquicio jurídico para conseguir los mejores beneficios y/u obviar las situaciones que puedan perjudicarles".

En el año 2012 el gobierno español llevó a cabo la reforma del mercado de trabajo más importante en cuanto a su dimensión y su profundidad, para lo cual optó por seguir como línea directriz la corriente económica ortodoxa, motivado y guiado por las distintas opiniones y recomendaciones que se hicieron desde organismos económicos de reconocido prestigio.

Del conjunto de normas que fueron aprobadas en dicha reforma, este artículo se ha centrado en examinar las que, o bien por cauces directos o bien por cauces indirectos, han atacado al salario de los trabajadores, demostrando que, en efecto, las leyes ejecutadas se han encargado de realizar una amplia y profunda devaluación salarial, respaldada en gran parte por la reducción de la jornada laboral a través de los Expedientes de Regulación Temporal de Empleo.

Sin embargo, los efectos positivos de la reforma del mercado de trabajo apenas se conocen. Las evoluciones de la población activa, inactiva, ocupada y parada, y la dinámica que ha experimentado la transición desde la inactividad al mercado laboral, así lo atestiguan.

$\mathrm{Y}$ es que, como este trabajo ha pretendido demostrar, el diagnóstico previo al año 2012 de la economía española que actuó como 
pilar maestro para llevar a cabo el cambio legislativo que regulara el mercado laboral, no fue del todo correcto. Dicho diagnóstico presentaba una situación en la que España adolecía, por una parte, de una espiral precios - salarios, y, por otra, de una notable pérdida de competitividad. Ambas cuestiones provocaban que el Producto Interior Bruto se situara por debajo de la producción potencial y que la tasa de paro fuera muy superior a la NAIRU. Desde esta perspectiva, parece lógico pensar que si se conseguía llevar a cabo una reducción de los salarios, todo este engranaje de acontecimientos negativos quedaría desmontado.

Sin embargo, ¿qué sucedería si la evolución de los salarios pactados no fuera el factor explicativo de los descensos en el nivel de producción y en el aumento de la tasa de paro, o si la pérdida de competitividad de la economía española no fuera tal, pese al saldo negativo de la balanza comercial, o si la superioridad de las importaciones sobre las exportaciones no estuviera motivada por la evolución de los costes laborales? En ese caso, el desenlace sería evidente: ninguno de los problemas quedaría solucionado, e incluso otros como la caída de la renta disponible y del consumo, y el consiguiente aumento del desempleo quedarían activados.

Y así parece que ha ocurrido, al menos hasta el momento en el que este artículo concluye, incumpliendo entonces esa norma general que aparecía al principio de este capítulo: una reforma laboral no debe crear más problemas de los que soluciona.

\section{Bibliografía}

Alvarez, I. y Luengo, F. (2011), "Competitividad y costes laborales en la UE: Más allá de las apariencias", ICEI Working Papers, WP02/11.

BBVA (2013), ¿Puede la moderación salarial reducir los desequilibrios económicos?", BBVA Research.

Bentolila, S. y Jimeno, J. F. (2003), "Spanish unemployment: The end of the wild ride?", FEDEA Documento de Trabajo 2003-10.

Bentolila, S. y Jansen, M. (2012), "Un primer análisis económico de la reforma laboral de 2012", Actualidad Laboral, 15 (2), Sección Estudios. 
Bhaduri, A. y Marglin, S. (1994), "Unemployment and the real wage: the economic basis por contesting political ideologies", Cambridge Journal of Economics, 14, 375 - 393.

Cebrián, I., Moreno, G y Pérez Infante, J. I. (2013), "Las reformas laborales en la obra de Luís Toharia", Revista de Economía Laboral, 10, $18-47$.

Comisión Europea (2011), Recomendación del consejo de 12 de julio de 2011 relativa al Programa Nacional de Reformas de 2011 de España y por la que se emite un dictamen del Consejo sobre el Programa de Estabilidad actualizado de España (2011-2014).

Dejuán, O. (1992), "El desempleo como resultado normal del funcionamiento normal de los mercados normales", Cuadernos de economia: Spanish Journal of Economics and Finance, 20 (57 - 58), 119 $-140$.

Dejuán, O. (1996), "Teoría sobre el empleo y el desempleo. ¿Explica alguna teoría la elevada tasa de paro española?", en O. Dejuán, J. Roca y L. Toharia, El desempleo en España. Tres ensayos críticos, Universidad de Castilla - La Mancha, 13 - 62.

Doménech, R. (2012), "Evolución del mercado de trabajo español: Reformas para el crecimiento económico, la generación de empleo y el refuerzo de la sostenibilidad del sistema de pensiones", BBVA Research, 2012.

Dolado, J. J. (2012), "The pros and cons of the latest labour market reform in Spain", Spanish Labour Law and Employment Relations Journal, 1 (1-2), 22 - 30.

Dolado, J. J., Jansen, M. y Jimeno, J. F. (2007), "A positive analysis of targeted employment protection legislation", IZA DP, 2679.

Fernández, M. J. (2014), "Devaluación interna y crecimiento de las exportaciones", Cuadernos de Información Económica, 242, 21 - 28.

Fondo Monetario Internacional (2010), "Country Report", 10/254.

Gobierno de España (2012a), Plan Nacional de Reformas. 
Gobierno de España (2012b), Actualización de Programa de Estabilidad $2012-2015$.

Jaumotte, F. (2011), "The Spanish labour market in a cross-country perspective", IMF Working Paper 11/11.

Kalecki, M. (1966), Studies in the theory of Business Cycles, 1933 - 1939. Blackwell.

Lavoie, M. (1992), Foundations of Post-Keynesian Economic Analysis, Edward Elgar Publishing.

Lavoie, M. (2014), Post-Keynesian Economics. New Foundations, Edward Elgar Publishing.

Layard, R., Nickell, S. y Jackmann, R. (1991), El paro: los resultados macroeconómicos y el mercado de trabajo, Centro de Publicaciones del Ministerio de Trabajo y Seguridad Social.

López, J. (2009), La economía de Michal Kalecki y el capitalismo actual: ensayos de teoría económica y economía aplicada, Fondo de Cultura Económica de España.

Maroto, A., Di Meglio, G., Visintin, S. y Rubalcaba, L. (2008), "Factores explicativos del comercio de servicios en Europa", Información Comercial Española, 844, 67 - 83

Ministerio de Empleo y Seguridad Social, (2013), Informe de Evaluación del Impacto de la Reforma Laboral, Ministerio de Empleo y Seguridad Social.

Muñoz de Bustillo, R. (1993), "Salarios, desempleo y calidad del empleo", en La Larga Noche Neoliberal: políticas económicas de los '80, Icaria-ISE.

Naastepad, C.W.M. y Storms, S. (2006), "OECD demand regimes (1960 2000)", Journal of Post-Keynesian Economics, 29 (2), 213 - 248.

OCDE (2010), "Moving beyond the job crisis", OECD Employment Outlook, 2010. 
Panigo, D. T. (2006), "Empleo y desempleo en la teoria postkeynesiana", em J. C. Neffa (dir.) Teorías Económicas del Mercado de Trabajo. I: Marxistas y Keynesianos, Fondo de Cultura Económica, Buenos Aires, $135-184$.

Patinkin, D. (1948), "Price flexibility and full employment", The American Economic Review, 38 (4), 543 - 564.

Paul, J. y Uxó, J. (2014), "Competitividad, devaluación interna y sector exterior", en A. Sánchez Andrés y J. A. Tomás Carpi (dirs.), Crisis política y económica en España. Un análisis de la política económica actual, Aranzadi.

Piore, M. (1983), Paro e Inflación. Perspectivas Institucionales y Estructurales, Alianza Editorial.

Stockhammer, E. (2011), "Crecimiento basado en los salarios: Introducción", en OIT "Hacía una recuperación sostenible: por una política de crecimiento basada en los salarios", Boletín de Investigación Sindical, 3 (2), 183 - 204.

Stockhammer, E., Onaran, Ö. y Ederer, S. (2009), "Functional income distribution and aggregate demand in the Euro área", Cambridge Journal of Economics, 33, 139 - 159.

Sylos-Labini, P. (1988), Las fuerzas del desarrollo y el declive, OikosTau.

Toharia, L. (2011), "El debate sobre las reformas necesarias para la economía española: el mercado de trabajo", Gaceta Sindical Comisiones Obreras, (nueva etapa) 17, diciembre, $201-236$.

Tomás, J. A. (1992), El desarrollo de la macro-policy. La teoría de la política económica de Keynes y Kalecki, Tirant lo Blanch. 